\title{
Altamira - oder: \\ Die Anfänge von Kunst und Kunstwissenschaft
}

\author{
ULRICH PFISTERER
}


Die Jahre 1879/80 müßten eigentlich für einen der radikalsten Wendepunkte in der Geschichte der Kunst und Kunstwissenschaft stehen - und spielen doch weder in den Fachdiskussionen der Jahrzehnte um 1900 noch heute eine herausragende Rolle. ${ }^{1}$ Voraussetzung dafür wäre freilich gewesen, daß die in der zweiten Hälfte des 19.Jahrhunderts um wissenschaftliche Anerkennung ringende Disziplin Kunstgeschichte ihre mühsam methodisch legitimierte, großenteils am Beispiel der italienischen Renaissance- und BarockKunst eingeschworene Blickrichtung gleich wieder grundlegend verändert hätte. ${ }^{2}$ Voraussetzung wäre ein für Fach-Kunsthistoriker kaum nachvoll-

Wolfgang Kemp und Charlotte Schoell-Glass danke ich für kritische Lektüre.

1 Ausnahmen bilden J. Rykwert: On Adam's House in Paradise. The Idea of the Primitive Hut in Architectural History, New York 1972, S. 32; W. Davis: Replications. Archaeology, Art History, Psychoanalysis, University Park (PE) 1996, v. a. S. 131-170 (,5. Beginning the History of Art“), der die Bedeutung von Anfangsszenarien für die Kunstgeschichtsschreibung bereits am Beispiel von Altamira und Lascaux analysiert, allerdings mit anderer Akzentsetzung und Zielrichtung; B. Küster: Matisse und Picasso als Kulturreisende. Primitivismus und Anthropologie um 1900, Berlin 2003, v. a. S. 56-61; und der Ausstellungskatalog Venus et Cain. Figures de la prébistoire 1830 1930, Paris/Bordeaux 2003 (mit diesen Aufsatz ergänzendem Material).

2 Vgl. H. Dilly: Kunstgeschichte als Institution: Studien zur Geschichte einer Disziplin, Frankfurt a. M. 1979; Ch. König, E. Lämmert (Hg.), Konkurrenten in der Fakultät: Kultur, Wissen und Universität um 1900, Frankfurt a. M. 1999; Hubert Locher: Kunstgeschichte als historische Theorie der Kunst 1750-1950, München 2001. 
ziehbarer Wandel der Blickrichtung hin zu ,Randbereichen' gewesen - auf die Bildzeugnisse der Prähistorie, der ,Primitiven ' und der Kinder. Umso unbefangener ließ dagegen offenbar die achteinhalbjährige María Justina den Blick schweifen, als sie ihren Großvater Marcelino Sanz de Sautuola 1879 bei der Besichtigung einer Höhle auf dessen Besitzungen in der Nähe der nordspanischen Küste bei Santander begleitete. Kenntnis von dieser Höhle hatte man schon seit etlichen Jahren, aber erst die kleine María Justina scheint in dem zu diesem Zeitpunkt noch nicht freigeräumten, teils nur knapp 1,30 m hohen Hauptraum des unterirdischen Gangsystems die Augen auf die Decke über ihr gerichtet zu haben, während alle Erwachsenen gezwungenermaßen nach vorne gebeugt allein den Boden erwartungsvoll nach vorgeschichtlichen Funden absuchten. Der Blickwechsel wurde jedenfalls mit der Entdeckung spektakulärer Höhlenmalereien belohnt - den ersten bis dahin überhaupt bekannt gewordenen Beispielen dafür (Abb. 1). ${ }^{3}$ Dem Fachpublikum machte der Privatforscher Marcelino Sanz de Sautuola den Fund im darauffolgenden Jahr mit einer kleinen Schrift Breves apuntes sobre algunos objetos prebistóricos de la provincia de Santander bekannt. ${ }^{4}$ Allerdings zunächst mit sehr geteiltem Echo, hielten die meisten Spezialisten die verblüffend naturnahen Malereien doch für moderne Fälschungen, von denen etwa die Farbe - wie ein Besucher der Höhle feststellte noch leicht mit dem Finger abzureiben gewesen sei. Erst durch zahlreiche Funde weiterer Höhlenmalereien in Spanien und Frankreich im Laufe der beiden folgenden Jahrzehnte neigte sich die Beweislast in den 1890er Jahren unausweichlich zugunsten von deren Echtheit: ${ }^{5}$ Altamira stieg zum

$3 \mathrm{Zu}$ diesen widersprüchlich überlieferten Vorgängen zusammenfassend B. Madariaga de la Campa: Sanz de Sautuola y el descubimiento de Altamira, Santander 2000.

4 Wiederabgedruckt in Escritos y documentos de Marcelino Sanz de Sautuola, hrsg. von B. Madariaga de la Campa, Santander 1976.

5 Ablehnend etwa E. Harlé: La grotte d'Altamira près de Santander (Espagne), in: Materiaux pour l'Histoire Primitive et Naturelle de l'Homme, 12, 1881, S. 275-283; die endgültige Wende markierte dann das Eingeständnis der Echtheit eines anderen, prominenten Kritikers, É. Cartailhac: Les cavernes ornées de dessins. La grotte d'Altamira, Espagne: ,Mea culpa' d'un sceptique, in: L'Anthropolgie, 13, 1902, S. 348. 
Synonym für den absoluten Anfang menschlicher Kunst im Paläolithikum auf.

Nun waren um 1879/80 die Diskussionen über das Wesen des prähistorischen Menschen zumindest in den Hauptzügen entschieden: gegen die Anhänger des biblischen Berichts (die - kurz gesagt - auf der Schöpfung des Menschen rund 5000-6000 Jahre v. Chr. beharrten) ebenso wie gegen die Verfechter wissenschaftlicher Kataklysmen-Theorien (vor allem im Gefolge George Cuviers) und zugunsten einer Evolutionsvorstellung über bis vor kurzem unvorstellbar lange, vorgeschichtliche Zeiträumen hinweg („deep time"). ${ }^{6}$ Die wichtigsten Publikationen für diesen Durchbruch lieferten George Lyell für die geologischen Erdalter (Principles of Geology, 18301833), Franz Bopp für die indogermanische Sprachgeschichte (Vergleichende Grammatik des Sanskrit, Zend, Griechischen, Lateinischen, Litthauischen, Gothischen und Deutschen, 1833-1852), Jacques Boucher de Perthes für die Koexistenz von fossilen, ,vor-sintflutlichen' Tieren und Menschen (seit den 1830er Jahren) und schließlich Charles Darwin für die evolutionäre Entstehung der Arten (Origin of Species, 1859). ${ }^{7}$ Und es waren zu diesem Zeit-

6 Zusammenfassend G. de Mortillet: Le préhistorique. Antiquité de l'homme, Paris 1883 (hier S. 364 f. auch ein kurzes Kapitel „Origine de l'art“).

7 Zu Lyell s. St. J. Gould: Die Entdeckung der Tiefenzeit. Zeitpfeil oder Zeitzyklus in der Geschichte unserer Erde, München/Wien 1990 und G. Bowker: Die Ursprünge von Lyells Uniformitarismus: Für eine neue Geologie, in: M. Serres ( $\mathrm{Hg}$.): Elemente einer Geschichte der Wissenschaften, Frankfurt a. M. 1994, S. 687-719. - Zu Boucher de Perthes Entdeckungen und seinen Argumenten lieferte er selbst eine konzise Zusammenfassung in: ders.: De l'homme antédiluvien et de ses œuvres, Paris 1860, hier S. 65-68 zu Tier- und Menschen-Bildwerken (ohne Verwendung des Wortes ,Kunst'), vgl. C. Cohen, J.-J. Hublin: Boucher de Perthes 1788-1868 - Les origines romantiques de la prébistoire, Paris 1989 und N. Richard, La fondation de la préhistoire, in: I. Poutrin (Hg.): Le XIX eiècle, Paris 1995, S. 43-65; noch 1863 vertrat dagegen etwa Louis Figuier in einem weitverbreiteten und mehrfach nachgedruckten Werk zur geologischen Entstehungsgeschichte der Erde und ihrer Flora und Fauna: La Terre avant le Déluge, Paris 1863, S. 357-372 die These, der Mensch sei erst nach der ,Eiszeit' entstanden; dann V. Meunier: Les ancêtres d'Adam. Histoire de l'homme fossile, Paris 1875. - Zu Darwin nur W. Lefèvre: Die Entstehung der biologischen Evolutionstheorie, Frankfurt a. M. u. a. 1984; T. Junker, U. Hoßfeld: Die Entdeckung der Evolution. 
punkt eigentlich auch schon genügend Artefakte zusammengetragen worden, die die prinzipielle manuelle Fertigkeit der, Vorläufer Adams', Troglodyten, vor-diluvialen, fossilen oder Ur-Menschen bewiesen: von Faustkeilen und Speerspitzen über Ritzzeichnungen auf Steinen und in Knochen bis hin zu kleinen Beinskulpturen. Fest stand jedenfalls, daß sich bereits die Menschen der Urzeit in der Bildgestaltung versucht hatten (Abb. 2). ${ }^{8} \mathrm{Ge}-$ rade beim traditionell wichtigsten künstlerischen Medium aber, der Malerei, war offenbar die Akzeptanz am schwierigsten, zumal die monumentalen (zumeist Tier-)Malereien in Altamira und anderswo mit ihrer genauen Naturbeobachtung, ihrer scheinbaren Lebendigkeit, Plastizität, den perspektivischen Elementen und souverän entworfenen Umrißlinien nicht nur unleugbar ein überragendes Können dokumentierten, sondern auch in neuer Intensität den Status von Kunstwerken zu reklamieren schienen (beides offenbar viel deutlicher, als dies für den Betrachter um 1900 bei den prähistorischen Knochen- oder Stein-Objekten mit Bildern der Fall war). Konsequenterweise wurden die Malereien Altamiras - nachdem sie gegen 1900 allgemein als echt anerkannt waren - dann auch einer kunsthistorischen Analyse und Klassifizierung unterworfen: Sie ließen sich etwa einer fossilen ,Künstlerschule und noch genauer: drei individuellen Händen zuschreiben und im Zusammenhang mit nachfolgenden Funden in die großen Entwicklungszyklen einer mehrtausendjährigen ,Kunstgeschichte

Eine revolutionäre Theorie und ibre Geschichte, Darmstadt 2001 und S. Weigel: Genea-Logik. Generation, Tradition und Evolution zwischen Kultur- und Naturwissenschaften, München 2006, v. a. S. 191-231.

8 É. Lartet, H. Christy: Cavernes du Périgord: Objets gravés et sculptés des temps préhistoriques dans l'Europe occidentale, in: Revue Archéologique, 9, 1864, S. 233-267; dies.: Reliquiae Aquitanicae, London 1865-1875; eine der ersten Erwähnungen dieser Artefakte in einer populären deutschsprachigen Publikation bei O. Fraas: Vor der Sündfluth! Eine Geschichte der Urwelt, Stuttgart 1866, S. 462-465 (die Illustrationen dieses Buches gehen großenteils auf Figuier [wie Anm. 7] zurück); É. Cartailhac: La France prébistorique, Paris 1889; H. Kühn: Kunst und Kultur der Vorzeit Europas, Berlin/Leipzig 1929, S. 42-197; A. Laming-Emperaire: Origines de l'archéologie préhistorique en France. Des superstitions médiévales à la décowverte de l'homme fossile, Paris 1964 (mit ausführlicher Chronologie und Bibliographie). 
prähistorischer Malerei‘ einordnen. ${ }^{9}$ Schon 1898 waren die beiden Gründungsschriften einer im Anspruch umfassenden ,Kunstgeschichte der Vorzeit' erschienen (allerdings noch ohne Erwähnung von Höhlenmalereien). ${ }^{10}$ Schließlich konnte die erste populärwissenschaftliche Publikation, die Altamira 1910 einem weiteren deutschsprachigen Publikum vorstellte, gar einen „Kunsttempel des Urmenschen“ ankündigen. ${ }^{11}$

Der Fund in Altamira und insgesamt die neu entdeckten steinzeitlichen Bildwerke veränderten so eigentlich alle Vorstellungen und Theorien über die ,Ursprünge und Anfänge der Kunst ${ }^{c}$ von Grund auf. Die Konsequenzen aus dieser radikalen Revision versucht mein Beitrag im folgenden zu skizzieren - immer auch vor dem Hintergrund der Frage, warum dieser Paradigmenwechsel so zögerlich zur Kenntnis genommen wurde. Es geht also nicht um die Frage nach den tatsächlichen Anfängen der Kunst und nicht um ein historisches Verständnis der Malereien Altamiras, sondern um die Relevanz des neuen Materials für die Konzeption des Anfangs in der ,großen Erzählung' des Faches um 1900 sowie um die methodischen Kon-

9 Künstlerschule und Händescheidung am weitesten geführt bei H. Alcalde del Rio: Las pinturas y grabados de las cavernas prehistóricas de la provincia de Santander. Altamira - Cavalanas - Hornos de la Pena - Castillo, Santander 1906, S. 18; die grundlegende Publikation zu Altamira von É. Cartailhac, H. Breuil: La caverne d'Altamira à Santillane près Santander, Monaco 1906; zu weiteren Entwicklungsstufen vorzeitlicher Kunst dann vor allem H. Breuil: L'Évolution de l'art pariétal des cavernes de l'âge du renne, in: Compte-rendue. Congrès Internationale d'Anthropologie et d'Archéologie prébistorique de Monaco, Foix 1907, S. 367-386, und ders.: L'Évolution de l'art quarternaire et les travaux d'Édouard Piette, in: Revue archéologique 1909, S. 378-411.

10 M. Hoernes: Urgeschicht der bildenden Kunst in Europa von den Anfängen bis um 600 vor Chr., Wien 1898; Th. Wilson: Prehistoric Art; or the origins of art as manifested in the works of prehistoric man, in: Report of the U.S. National Museum for 1896, Washington 1898, S. 325-664 (auch eigenständig erschienen). - Vgl. dann mit Erwähnung der Höhlenmalereien etwa É. Piette: L'art pendant l'àge du renne, Paris 1907 und C. Schuchardt: Alteuropa in seiner Kultur- und Stilentwicklung, Straßburg/Berlin 1919, zu Altamira S. 27-29.

11 A. Stiegelmann: Altamira. Ein Kunsttempel des Urmenschen, Godesberg-Berlin 1910. 
sequenzen und um das Selbstverständnis der Kunstgeschichte in Relation zu den anderen Fächern, die sich ebenfalls mit diesen Bildzeugnissen beschäftigten. ${ }^{12}$ Dabei werden nicht nur die Entwürfe eines ,Ursprungs der Kunst ' in Text und Bild analysiert (in den ersten beiden Kapiteln), sondern es gilt auch zu zeigen (in den folgenden drei Kapiteln), daß entscheidende methodische Grundlagen der Disziplin: vergleichende Typenreihen, die Frage nach der Rolle der Frau für die Kunst und schließlich das Verständnis von historisch und ethnisch bedingten ästhetischen Kategorien und dem Aufgabenfeld der Kunstgeschichte insgesamt durch die Herausforderung prähistorischer Bildwerke entscheidend angeregt wurden. So verstanden, markiert Altamira nicht nur den Anfang der Kunst, sondern in wichtigen Aspekten auch den Anfang der Kunstwissenschaft, wie sie um 1900 als neue Zusammenführung von Theorie und historischem Material postuliert wurde.

\section{Ursprungsphantasien - Anfangstheorien}

Wann, wo und von wem wurden die menschlichen Techniken, Wissenschaften und Künste erfunden? Fragen und Antworten dazu kursierten in etwa seit Hesiod und dem 6. Jahrhundert v. Chr. in Griechenland; ganze ,Erfinder-Kataloge ${ }^{6}$ überliefern und diskutieren Hygin, Plinius und einige Autoren v.a. des griechischen Frühchristentums; spätestens mit dem 14./15. Jahrhundert dachte man dann in schriftlicher Form wieder und speziell auch über die Anfänge der Bildkünste nach. ${ }^{13}$ Das erste im Druck

12 Vgl. zu den Postulaten und Mechanismen von Anfangs-Konstruktionen neben Davis [wie Anm. 1] auch E.W. Said: Beginnings. Intention and Metbod, New York 1975, etwa S. 50-68; O. Hazan: Le mythe du progrès artistique, Montréal 1999; Ch. Kruse: Wozu Menschen malen. Historische Begründungen eines Bildmediums, München 2003; A. Koschorke: Vor der Gesellschaft. Das Anfangsproblem der Anthropologie, in: B. Kleeberg u.a. (Hg.): Urmensch und Wissenschaft. Eine Bestandsaufnabme, Darmstadt 2005, S. 245-258, und ders.: Zur Logik kultureller Gründungserzählungen, in: Zeitschrift für Ideengeschichte, 1/2, 2007, S. 5-12.

13 K. Thraede: Erfinder II (geistesgeschichtlich), in: Th. Klauser (Hg.): Reallexikon für Antike und Christentum, Bd. 5, Stuttgart 1962, Sp. 1191-1278. 
erschienene Nachschlagewerk zu diesem Thema von Polydorus Vergilius De inventoribus rerum (1498) mit eigenen Kapiteln zu den Erfindern von Malerei und Skulptur - konnte so in der Frühen Neuzeit ein vielfach wiederaufgelegter und übersetzter Verkaufserfolg werden, an den letztlich noch im Frankreich des 18. und früheren 19. Jahrhunderts zwei umfangreiche Lexika anzuknüpfen versuchten - das Dictionnaire des Origines, on Epoques des Inventions ... des Antoine J. B.A. d'Origny (1777) und das Nouveau dictionnaire des origines, inventions et découvertes ... des François Noël (1827). Großen Absatz fanden seit dem späten 16. Jahrhundert auch die ähnlich gelagerten Publikationen zu den ,Erfindungen' der Neuzeit, die im Streit zwischen antiqui und moderni Argumente für beide Seiten lieferten. ${ }^{14}$ Es überrascht jedenfalls kaum, daß während dieser zwei Hochphasen des Interesses am Menschen - Humanismus und Aufklärung/ Romantik - auch das Interesse am (,wilden“, ,primitiven') „Ursprung der Gesetze, Künste und Wissenschaften“ je eine zentrale Rolle spielte. ${ }^{15}$ Wobei klar sein muß, daß die Frage nach der Entstehung nicht nur als wissenschaftlich unerläßlich für die Wesensbestimmung und Definition einer Sache angesehen wurde (gemäß dem Gedanken, daß sich alle Grundprinzipien am Anfang in besonderer Deutlichkeit und einfachen Klarheit zeigten), sondern mit dem Anspruch auf Ursprung und Erfindung ganz wesentlich Stolz und Selbstverständnis der Nationen verbunden sein konnten. ${ }^{16}$

14 Dazu etwa C. Atkinson: Inventing Inventors in Renaissance Europe. Polydore Vergil's, De inventoribus rerum' (1499 and 1521), Tübingen 2007 und M. Fumaroli: Les abeilles et les araignées, in: A.-M. Lecoq (Hg.): La Querelle des Anciens et des Modernes, Paris 2001, S. 7-220.

15 So der Titel der 1760-62 publizierten deutschen Übersetzung von A.Y. de Goguet: De l'Origine des lois, des arts et des sciences ..., Paris 1758, 3 Bde.; insgesamt K.-H. Kohl: Entzauberter Blick. Das Bild vom guten Wilden, Frankfurt a. M. 1986; vgl. für das 19. Jh. etwa A. Petit: Étudier „'embryogénie de l'esprit humain“, in: Poutrin [wie Anm. 7], S. 277-293.

16 M. Rothstein: Etymology, Genealogy, and the Immutability of Origins, in: Renaissance Quarterly, 43, 1990, S. 332-347; Carus Sterne: Natur und Kunst. Studien zur Entwicklungsgeschichte der Kunst, Berlin 1891, S. 137: „[...] Enthusiasten, die aus einzelnen, vortrefflich wiedergegebenen Thierbildern folgerten, daß Frankreich 
Bei allem sonstigen Erkenntniszuwachs, den das 18. und frühe 19. Jahrhundert der Renaissance voraus hatte, hinsichtlich der Frage ,Anfänge der Bildkünste ' blieben die prinzipiellen Zugangsmöglichkeiten weitgehend die gleichen, wollte man die origo artium nicht sowieso lieber im Dunkeln lassen, wie es einige Autoren für klüger hielten. ${ }^{17}$ Weiterhin spielten jedenfalls aitiologische Mythen - insbesondere die Erzählung über die Tochter des griechischen Töpfers (Di-)Butades, die den Schatten ihres Liebsten an der Wand umzeichnete - eine zentrale Rolle, schien doch unter deren leicht durchschaubarem Schleier eine naturgegebene, ,logische Erklärung für die Anfänge der Bildkünste geliefert. Just diese in der Kunstliteratur vielfach wiederholte Legende vom, Ursprung der Malerei' stieg dann überhaupt erst in den Jahrzehnten zwischen ca. 1770 und $1830 \mathrm{zu}$ einem bevorzugten Bildthema auf. ${ }^{18}$ Und wenn nach 1830 wissenschaftlichere Erklärungsver-

schon in jener grauen Vorzeit an der Spitze der Kulturnationen gestanden habe"; F. Behn: Der Mensch der Urzeit, seine Kunst und seine Kultur, Leipzig [1913], S. 5: „Nach einem kurzen Vorspiel auf der Insel Java beginnt das eigentliche Drama der Menschwerdung auf deutschem Boden“ - nämlich angeblich durch den 1907 bei Mauer gefundenen Unterkiefer des Homo Heidelbergensis. - Vgl. auch S. Brather: Ethnische Identitäten als Konstrukte der frühgeschichtlichen Archäologie, in: Germania, 78, 2000, S. 139-177; I. Wiwjorra: „Ex oriente lux“ - „Ex septentrione lux“. Über den Widerstreit zweier Identitätsmythen, in: A. Leube (Hg.): Prähistorie und Nationalsozialismus, Heidelberg 2002, S. 73-106.

17 Stellvertretend dafür J. H. Zedler: Grosses vollständiges Universal-Lexicon aller Wissenschaften und Künste ..., Bd. 19, Halle und Leipzig 1739, Sp. 259-269, s.v. ,Mahler-Kunst', hier Sp. 260: „Es mag die Mahler-Kunst, wie viele andere Künste, einen geringen Anfang gehabt haben, indem der Schatten eines Mannes an der Wand mit einer Kohlen oder Kreiden umzogen, ihr den ersten Anfang gegeben haben soll: gleichwie auch anfänglich nur eine Farbe gebraucht worden. Jedoch wer sie zuerst erfunden, kan wegen ihres Alterthums nicht genau entschieden werden. Die Egyptier dürffen sich rühmen daß dieselbe bey ihnen bereits $6000 \mathrm{Jahr}$ im Schwange gewesen, ehe man was davon in Griechenland gewußt, wie Plinius Hist. nat. lib. XXXV. cap. 3 meldet. Wie nichtig aber dieses Vorgehen sey siehet ein ieder gar leicht ein, zumahl wenn man bedenckt, daß die Welt vorietzo noch nicht $6000 \mathrm{Jahr}$ gestanden."

18 R. Rosenblum: The Origin of Painting: A Problem in the Iconography of Romantic Classisicm, in: Art Bulletin, 39, 1957, S. 279-290 und G. Levitine: Addenda to Robert Rosenblum's 'The Origin of Painting ...', in: ebd., 40, 1958, S. 329-331. - Zu 
suche zunehmend die antiken Legenden ablösten, dann heißt das nicht, daß mythische Denkmodelle insgesamt verabschiedet wurden. Vielleicht am deutlichsten kann dies die 1870 publizierte Geschichte des menschlichen Wohnens von Eugène-Émanuele Viollet-le-Duc demonstrieren, die unter der Überschrift „Sont-ce des hommes?" mit einer frei erfundenen Erzählung zu Épergos und dessen ,Erfindung“ der Urhütte einsetzt - wobei suggeriert wird, daß durch dieses Ereignis die zuvor wilden „Wesen von ungeschlachtem Körperbau, hell-geblicher Haut und einem von wenigen schwarzen Haaren bedeckten Kopf“ überhaupt erst zu Menschen transformiert wurden, deren noch unkultivierte Gesichtszüge die das Kapitel abschließende Vignette zeigt (Abb. 3). ${ }^{19}$ Die weiteren Zugangsmöglichkeiten, die Frühe Neuzeit und die Jahrzehnte um 1800 miteinander teilten, waren antike nicht-mythische Schriftzeugnisse, spekulative Geschichts- und Ästhetiktheorie und der Befund sichtbarer Denkmäler früher Kulturen (von Stonehenge über die Pyramiden bis zu den Tempeln Indiens). Aus keinem dieser Bereiche ließ sich eine wirklich gesicherte (chronologische) Basis gewinnen, so daß für alle daraus abgeleiteten Thesen praktisch genauso überzeugende Gegenargumente gefunden werden konnten: Bedienten sich die menschlichen Bildkünste zuerst des Zeichnens oder des plastischen Bildens oder gar der Architektur, die als Schutz vor Umwelt und Witterung am notwendigsten war? ${ }^{20}$ Kann überhaupt die Not und der Mangel als Auslöser menschlicher Kunstübung gesehen werden, wie es etwa das antike Sprichwort „paupertas gignit artem“ formulierte, oder aber manifestiert sich in der Kunst nicht ein dem Menschen eingeborener, zweckfreier Nach-

anderen vormodernen Aitiologien s. M. Bettini: Il ritratto dell'amante, Turin 1992 und Kruse [wie Anm. 12].

19 E.-É. Viollet-le-Duc: Histoire de l'habitation humaine, Paris 1870, S. 4-7; dazu Rykwert [wie Anm. 1], S. 37-42 und ein etwas früheres Vergleichsbeispiel S. 74. P. Boitard: Paris avant les hommes ..., Paris 1861 bemüht für sein Werk die Fiktion, ein Flaschenteufel habe den Autor in die Urwelt transportiert und ihm erläutert „ce qu'était Paris avant les hommes".

20 Für die Präzedenz der Architektur plädiert etwa Hegel in seiner Ästhetik, aber auch C. Schnaase: Geschichte der bildenden Künste, Düsseldorf 1843-1864, zit. Bd. 1, ${ }^{2} 1866$, S. 55 f. oder F. B. de Mercey, Études sur les beaux-arts depuis leur origine jusqu'a nos jours, Paris 1855 , Bd. 1, S. 31-33. 
ahmungs- und Schönheitstrieb, wie es ebenfalls bereits in der Antike Aristoteles andeutete? Standen schließlich die hochgradig stilisierten, einfachen` Bildwerke Ägyptens oder aber die ,kleinteilig-chaotischen' an indischen Tempeln am Anfang der menschlichen Kunstübung? ${ }^{21}$ Vor diesem Diskussionshintergrund sind jedenfalls die weltumfassenden GeschichtsEntwürfe eines Herder, Hegel oder Auguste Comte zu sehen, die wiederum die ersten ,umfassenden Kunstgeschichten " von Wilhelm Kugler, Carl Schnaase und letztlich auch den eher anthropologischen Zugang Francis Pulszkys beeinflußten.

Allein eine Annahme lag allen diesen widersprüchlichen Theorien zugrunde: daß sich die Gesamtentwicklung einer Kultur und Kunst mit der biologischen Metapher eines Lebewesens fassen lasse und alle Anfänge, also auch die ,Kindheit der Zeichnung, Malerei und Skulptur' einfach, unvollkommen, von mangelhaftem technischem wie mimetischem Können zu sein haben, ja, für manche Autoren eigentlich noch gar nicht als ,Kunst bezeichnet werden dürfe. Diese Überzeugung eröffnet noch 1842 Franz Kuglers Handbuch der Kunstgeschichte mit seinem Anspruch einer ,Kunstgeschichte aller Zeiten und Völker`. Unter der Überschrift „Vorstufen der künstlerischen Gestaltung“, Unterkapitel „Ursprung“, heißt es:

„Die Urzustände des menschlichen Geschlechts sind Zustände der Kindheit. Die Sorge des Denkens ist noch fern. Doch sind die Triebe thätig, durch welche das Geschlecht zum Schaffen angeregt wird. Das Bedürfnis des Lebens giebt Anlass zu mannigfachen Einrichtungen, die Freude am Leben zu buntem Schmuck. Die Gebilde der Natur, die der Mensch für seine Zwecke verwendet, die Eigenheiten des Stoffes, den er bearbeitet, die Lust zur Nachahmung von ergötzlichen Dingen, die er um sich erblickt, sind der Grund von allerlei Gestaltung. Aber zur Kunst führt dieses Schaffen nicht. Dann kommt

21 A. Riem: Über die Malerei der Alten, Berlin 1787, das Kapitel I. Von dem Ursprung und Anfang der Kunst, hier v. a. S. 3-5 und 11-15 gegen Winckelmann und Caylus und mit der ethnographischen Parallele mittelamerikanischer Malerei: „Diesen kleinlichen Styl finden wir bei den ersten und ältesten Werken der Kunst unter den Egyptiern sowohl, als den Indern, und eben dieser chargirte, überladene Styl, ist ein Beweiss ihres höheren Alterthums. Simplicität, mit bewunderungswürdiger Hoheit verbunden, wie sich CAYLUS ausdrückt, ist das Werk der höchsten Ausbildung der Kunst, des reinsten Geschmacks, und der grösten Cultur; [...].“ - Vgl. dagegen Schnaase [wie Anm. 20], S. 56 f. 
die Stunde, dass dem Menschen die geistigen Mächte des Lebens kund werden. Die Gottheit offenbart sich ihm, [...]. Das Ausserordentliche ist in das Leben des Menschen getreten: - er bereitet dem Gedächtnisse desselben, damit es bleibe, an der Stätte seiner Erscheinung ein festes Mal, - ein Denkmal. [...]. Im Denkmal ist ein geistig Empfundenes durch ein sinnliches Mittel dargestellt. Dies ist der Beginn der Kunst. [...]. Die ersten Denkmäler, welche errichtet wurden, waren naturgemäss von einfachster Beschaffenheit. Aufgethürmte Erdhügel, aufgerichtete Steinmassen bezeichneten die geweihten Stätten. [...] Der grösste Reichthum dieser urthümlichen Denkmäler findet sich im Norden, auch im Westen Europa's, in den Sitzen der keltischen und der nordgermanischen Volksstämme." 22

Angesichts dieser hochspekulativen Erklärungsmodelle wird die wissenschaftliche Überzeugungskraft der Theorien Gottfried Sempers verständlich, die 1860-63 in sein Hauptwerk Der Stil münden: Für seine bekannte Ableitung der Anfänge jeglicher Kunstübung aus einem funktionalen Bedürfnis, auf dessen Realisierung weitere Faktoren wie Material und Technik einwirken, kann er sich auf das Vorbild naturwissenschaftlicher Klassifizierung und auf sprachwissenschaftliche Untersuchungen stützen. Trotz seines Bemühens um „die Urzustände der menschlichen Gesellschaft “ scheint Semper aber von prähistorischer Kunst noch nichts gehört zu haben, die ältesten ihm bekannten Kunstwerke stammen weiterhin aus Ägypten. ${ }^{23}$ Der Wirkung des häufig vereinfacht rezipierten Semperschen

22 F. Kugler: Handbuch der Kunstgeschichte, Stuttgart ${ }^{3} 1856$, S. 1 f.; vgl. dagegen und ebenfalls mit dem Anspruch, einen Überblick der, Weltkunstgeschichte' in enger Zusammenarbeit mit den neuen anthropologischen Forschungen zu geben, F. Pulszky: Iconographic Researches on Human Races and Their Art, in: J. C. Nott, Geo. R. Glidden (Hg.): Indigenous Races of the Earth, London/Philadelphia 1857, S. 87-202, hier die Zitate S. 100 und 102.

23 G. Semper: Der Stil in den technischen und tektonischen Künsten ..., 2 Bde., Frankfurt a.M./München 1860-1863; das Zitat aus ders.: Die vier Elemente der Baukunst. Ein Beitrag zur vergleichenden Baukunde, Braunschweig 1851, S. 54; G. Klemm: Allgemein Culturgeschichte der Menschheit, 10 Bde., Leipzig 1843-1852; ders.: Die Werkzenge und Waffen. Ibre Entstehung und Ausbildung, Sondershausen 1858. Dazu S. Hildebrand: „nach einem Systeme zu ordnen, welches die inneren Verbindungsfäden dieser bunten Welt am besten zusammenhält" Kulturgeschichtliche Modelle bei Gottfried Semper und Gustav Klemm, in: H. Karge (Hg.): Gottfried Semper-Dresden und Europa, München/Berlin 2007, S. 237-250. 
Funktionalismus schadet dies nicht - im Gegenteil: 1870 verbindet der Archäologe Alexander Conze in seiner einflußreichen Zusammenschau zu den ,Anfängen der Kunst' im griechischen und nordischen Bereich, die für ihn erst mit der Bronze- und Eisenzeit beginnen, die Thesen Sempers mit neuen Erkenntnissen zur Entwicklung der indo-germanischen Sprachen. So scheinen nicht nur dies- und jenseits der Alpen die Künste ihren „technische[n] Ursprung“ in der Weberei zu besitzen, sondern dies wird nun auf ihre ehemalige "gemeinsame Heimat" zurückgeführt. Weiterhin gilt auch noch für Conze, daß sich die Kunst aus geometrisch-abstrahierten Anfängen erst langsam zur Naturnachahmung aufschwingt. ${ }^{24}$

Diese Diskussionsbasis zu den Anfängen menschlicher Kultur und Kunst änderte sich nun mit der Einsicht in die ,Tiefenzeit' der Evolution und die damit einhergehende, richtige Einordnung vorgeschichtlicher Funde in bis dato ungeahnte Zeitenferne radikal: Erste Grabungen und Publikationen zu prähistorischen Relikten und Werkzeugen setzten mit den 1830er Jahren durch den Amateur-Forscher Jacques Boucher de Perthes ein, sie gipfelten 1857 in seinem Hauptwerk der Antiquités celtiques et antédiluviennes. ${ }^{25}$ Die ersten Überreste von Versuchen dieser Urmenschen, Ritzzeichnungen

24 A. Conze: Zur Geschichte der Anfänge griechischer Kunst, Wien 1870, hier S. 18 und 25 die Zitate, und eine Ergänzung unter demselben Titel, Wien 1873; einen Kontrast der scheinbar ,geometrischen ' Anfänge der Urkunst und den ,primitiven" naturalistischen Bildwerken amerikanischer Indianer konstatiert D. Wilson: Prebistoric Man, London 1862 [zit. ${ }^{3} 1875$, Bd. 1, S. 356 f.].

25 J. Boucher de Perthes: Antiquités celtiques et antédiluviennes, 3 Bde., Paris 18471864; vgl. auch Boucher de Perthes [wie Anm. 7] zu seinen Publikationen seit den 1830er Jahren. Neben den vielen Legenden zu urzeitlichen Objekten (É. Cartailhac: L'âge de la pierre dans les souvenirs et les superstitions populaires, Paris 1877) schrieb allerdings bereits im späten 16. Jh. Michele Mercati in seiner erst 1717 gedruckten Metallotheca die Feuersteinobjekte richtig den „ältesten Menschen“ zu. Die erste entscheidende Übersicht zu diesen, Vorläufern' und Boucher de Perthes’ Bedeutung von E.-Th. Hamy: Précis de paléontologie humaine, als Anhang zu: George Lyell: L'ancienneté de l'bomme prouvée par la géologie ..., Paris ${ }^{2} 1870$ (dann als eigenständiges Buch noch im gleichen Jahr, Paris 1870); Laming-Emperaire [wie Anm. 8]; Cohen, Hublin [wie Anm. 7]. 
auf Steinen und Knochen herzustellen, aber auch kleine Statuetten ließen dann nicht lange auf sich warten. Die enthusiastischen Reaktionen darauf führten zunächst zu einer Semper diametral entgegengesetzten Sicht auf Kunst als Wesensmerkmal und zweckfreiem ,Schmuck- und Schönheitstrieb“ des Menschen: „Mithin ist der ersten Entwicklung der materiellen Civilisation die Kunst vorhergegangen. Von dieser Urperiode an hat sich der Mensch als Künstler und Kenner des Schönen gezeigt, wiewohl er noch keineswegs aus dem wilden Leben geschieden war. Und diese göttliche Fähigkeit, mit welcher der Herr ihn ausstattete, als er in ,zu seinem Ebenbilde' schuf, war zuerst in ihm wach geworden, bevor er noch das Bedürfnis verspürt hatte, seine harten Lebensverhältnisse zu bessern. “26 Den

26 Entscheidend die Publikation Lartet, Christy [wie Anm. 8]; das Zitat von F. Lenormant: Die Anfänge der Kultur, Bd. 1: Vorgeschichtliche Archäologie. Agypten, Jena 1875 (frz. 1873; darin S. 46-115: „Die Denkmäler der neolithischen Periode. Erster Gebrauch der Metalle und ihre Einführung im Westen"; dieses Kapitel zuerst in: Gazette des Beaux-Arts, 23, Dez. 1867, S. 499-523); vgl. H. Le Hon: L'homme fossile en Europe. Son industrie, ses mœurs, ses ouvres d'art, Brüssel/Paris 1868, S. 70 zur ersten, 1864 von Lartet und Christy publizierten prähistorischen Ritzzeichnung: "Cette précieuse relique [...] nous prouve que l'art est aussi ancien que notre race et que de tout temps, même dans l'état sauvage, il s'est rencontré des organisations spéciales, aptes à être vivement impressionnées et à reproduire leurs impressions avec une justesse qui parfoit nous étonne." Schnaase [wie Anm. 19], S. 50: „Auch die Kunst gehört zu den nothwendigen Aeusserungen der Menschheit; ja man kann vielleicht sagen, dass in ihr der Genius der Menschheit sich noch vollständiger und eigenthümlicher ausspreche, als in der Religion selbst, weil in dieser immerhin die Form des Gedankens oder doch des vergeistigten Gefühls vorherrscht, während in der Kunst auch die sinnliche Natur vollkommen mit augenommen und befriedigt ist. Kein Volk ist daher auch ganz ohne Kunst, sie findet sich unbewusst ein; aber freilich sind bei Weitem nicht alle Völker im Besitze der ganzen Kunst oder aller Künste, [...].“ M. Carriere: Die Kunst im Zusammenhang der Culturentwicklung und die Ideale der Menschbeit, 2 Bde., Leipzig 1871, Bd. 1, S. 124: „Religiöses Gefühl, sittliche Begriffe in der Unterscheidung von gut und böse, das Gewissen, ein aufdämmerndes Streben nach Erkenntnis in der Deutung der Erscheinungen und ihres Zusammenhangs in der Welt bilden neben dem Sinn fürs Schöne so sehr die Grundlage alles Menschlichen, daß wir sie bei allen Naturvölkern entdecken." Schließlich am dezidiertesten W. Bölscher: Die Abstammung der Kunst, Stuttgart 1926. 
„Zweck dieser Bilder [...] muß [man] sich [...] aus ihnen selbst zu beantworten suchen. Eine Bilderschrift können sie gewiß nicht vorstellen, weil die einzelnen Bilder offenbar ohne alle Beziehung zu einander stehen. [...] Wahrscheinlich sind sie die zufälligen Produkte momentaner Regungen eines künstlerischen Dranges, und vielleicht sind sie bei Gelegenheit großer Versammlungen [...] nur zum Vertreib der Zeit entstanden. “ ${ }^{27}$ Entscheidende Bestätigung schien diese Position eines l'art pour l'art auch aus dem Umstand zu ziehen, daß Bildwerke in chronologischen Strata neben und noch vor dem Auftauchen von Ornamenten nachzuweisen waren, also auch hier die ältere Vorstellung, wonach sich der künstlerische Trieb der Menschen zunächst an ornamentalem Schmuck (seinerseits mit funktionalen Reminiszenzen) und erst später an Figürlichem versucht habe, falsifiziert war. Diese Reihenfolge zeigte sich exemplarisch auch in der Höhle von Altamira: Deren Malereien umfassen nur ganz wenige, kaum entwickelte ornamentale Formen. ${ }^{28}$

Die bei allem Finderglück weiterhin mehr als spärlichen Kenntnisse in praktisch allen Bereichen über die menschlichen Vorfahren der Steinzeit versuchten die Forscher dabei durch ein Verfahren auszugleichen, das bereits im 18. Jahrhundert erprobt worden war, nun aber spätestens 1862/65 mit David Wilsons Prehistoric Man und John Lubbocks Prehistoric times, as illustrated by ancient remains and the manners and customs of modern savages, wo es schon im Titel ankündigt wurde, weite Verbreitung fand. ${ }^{29}$ Gemeint ist das Verfahren der ethnographischen Parallelen, bei dem die

27 W. Baer: Der vorgeschichtliche Mensch, Leipzig 1873-74, Bd. 1, S. 147 f. zur Entdeckung von alten Felsmalereien an der Südspitze Afrikas, die in seiner Argumentation als ethnographische Parallele die vorgeschichtliche Kunst erhellen sollen.

28 Zusammenfassend dazu Hoernes [wie Anm. 10], S. 24-61.

29 Dazu Rykwert [wie Anm. 1], S. 136 f.; Kohl [wie Anm. 15]; Laming-Emperaire [wie Anm. 8], S. 86-90; S. Hansen: Von den Anfängen der prähistorischen Archäologie. Christian Jürgensen Thomsen und das Dreiperiodensystem, in: Prähistorische Zeitschrift, 76, 2001, S. 10-23; A. B. Kehoe: The Invention of Prehistory, in: Current Antbropology, 32, 1991, S. 467-476; A. B. Stahl: Concepts of time and approaches to analogical reasoning in historical perspective, in: American Antiquity, 58, 1993, S. 235-260. 
Verhältnisse der ,primitiven Völkern' der jetzigen Welt in erklärende Analogie zu den vermuteten Verhältnissen des vorgeschichtlichen Europas gesetzt wurden. Die ,Anfänge der Kultur und Kunst' ließen sich so aus vergleichenden Studien der Vorzeit, der Primitiven und letztlich auch der Kinder erhellen, alles drei Repräsentanten eines ,anfänglichen Denkens ‘ allerdings ergab sich damit letztlich auch die Konsequenz, daß nun eine ganz neue Form über Europa hinausreichender, Weltkunstgeschichte' zu betreiben war. ${ }^{30}$ Ein deutschsprachiges Resümée dazu lieferte etwa Carus Sterne alias Karl Kraus in seinem vielgelesenen Buch Natur und Kunst. Studien zur Entwicklungsgeschichte der Kunst von 1891: „Es finden sich [...] zweierlei ziemlich gleichwerthige Gelegenheiten, die ersten Aeußerungen des Kunsttriebes beim Menschen zu beobachten, nämlich einerseits bei den heute noch auf niederer Stufe verharrenden Naturvölkern und andrerseits in den hinterlassenen Fußstapfen des prähistorischen Menschen fast seit den ältesten Zeiten seines Auftretens. Soweit der Letztere Spuren künstlerischer Bethätigung zurückgelassen hat, sind seine Leistungen denen noch heute lebender uncivilisierter Völker so ähnlich, daß beide sich gegenseitig erläutern [...].“ ${ }^{31}$ Entscheidend war für dieses Theoriemodell jedenfalls, die „uncivilisierte[n] Völker“ außerhalb Europas nicht mehr wie bislang als Resultat eines ,Dekadenz-Prozesses“ (ehemals höher entwickelter Kulturen) zu begreifen, sondern eine bei allen Menschen prinzipiell einheitlich verlaufende ,kulturelle Evolution' anzunehmen, die bei diesen VöIkern aufgrund ungünstiger Faktoren gleich zu Beginn stehen geblieben oder doch zumindest im Vergleich zu Europa stark verlangsamt worden war. Aus dieser Konstellation resultierte dann ab den 1860er Jahren eine wahre Flut von Publikationen zur Urgeschichte des Menschen und den Anfängen der Kultur. ${ }^{32}$

30 Zum neuen Interesse an Kinderkunst E. Pernoud: L'invention du dessin d'enfant en France, à l'aube des avant-gardes, Paris 2003; zu den Dynamiken für, Weltkunstgeschichts'-Forschung um 1900 s. U. Pfisterer: Origins and Principles of World Art History - 1900 (and 2000), in: K. Zijlmans, W. van Damme, World Art Studies, Leiden 2008 (im Druck).

31 Sterne [wie Anm. 16], S. 135 f.

32 Neben den hier in anderen Anmerkungen zitierten Titeln etwa Otto Caspari: 
Wer dagegen nicht bereit war, einen dem Menschen von seinem Uranfang an innewohnenden künstlerischen Impuls zuzugestehen oder zumindest die Produkte nicht gleich als, vollwertige Kunst' anzuerkennen, für den zeichneten sich drei Strategien ab, die neu gefundenen prähistorischen Bildwerke mit weniger radikalen Denkmodellen in den Griff zu bekommen: Zunächst ließen sich bei allem Staunen über das Alter der Objekte die eingeritzten Umrißzeichnungen in Stein und Knochen, die teils mehrere Tierfiguren einfach übereinander blendeten, wie auch die kleinen Bein-Figürchen mit ihren überzeichneten Proportionen letztlich doch als , primitiv' charakterisieren, mangelhaft in ihrer Mimesis und damit zumindest einer der bisherigen a priori-Forderungen an die, Anfänge der Kunst ${ }^{6}$ entsprechend. ${ }^{33}$ Die Entdeckung Altamiras 1879/80 und der anderen prähistorischen Höhlenmalereien mit ihrem überraschenden technischen und mimetischen Niveau entzog diesem Argumenten schlagartig

Die Urgeschichte der Menschbeit mit Rücksicht auf die naturliche Entwicklung des frübesten Geisteslebens, Leipzig 1873, 2 Bde.; A. Rauber: Urgeschichte des Menschen. Ein Handbuch für Studierende, Leipzig 1884, 2 Bde. (mit Kapiteln zu Werkzeugen, Keramik, Bekleidung und Schmuck usw.); A. de Quatrefages de Bréau: Hommes fossiles et hommes sauvages: étude d'anthropologie, Paris 1884; H. du Cleuziou: La Création de l'Homme et les Premiers Ages de l'Humanité, Paris 1887 (mit vielen Abb.); M. Hoernes: Urgeschichte des Menschen, 1892; Ph. Salmon: L'âge de la pierre, Paris 1894. - Vgl. St. Cartier: Licht im Dunkel des Anfangs. Studien zur Rezeption der Prähistorik in der deutschen Welt- und Kulturgeschichtsschreibung des 19. Jahrhunderts, Herdecke 2000.

$33 \mathrm{Vgl}$. die unterschiedlich gewichteten Urteile etwa von Fraas [wie Anm. 8], hier S. $463 \mathrm{f}$. zu den „ersten und rohesten Kunstdenkmale[n], eingravierte[n] Thierfiguren auf Knochen und Geweihstücken von Rennthier und Riesenhirsch"; F. Ratzel: Vorgeschichte des europäischen Menschen, München 1874, S. 69-73; N. Joly: Der Mensch vor der Zeit der Metalle, Leipzig 1880, S. 343-373 unter der Überschrift „Die schönen Künste“, hier v. a. S. 344 und 362: „Einige dieser Werke, die in den Augen eines ungebildeten und unwissenden Beschauers einen höchst zweifelhaften Werth haben, aber für den Mann der Wissenschaft, den Kunstkenner und namentlich auch für den Künstler unberechenbare Schätze sind, wollen wir näher betrachten. [...] Trotz ihrer augenfälligen Mängel haben diese Zeichnungen, diese Sculpturen unserer ältesten Künstler dennoch nicht die Steifheit der ägyptischen Bilderwerke der ersten Dynastien." 
allen Boden - weshalb eben die Akzeptanz dieser Malereien der Forschung teils so schwer fiel. Für die nun noch irritierendere, ,hochstehende' Kunstübung der,primitiven' Urmenschen wurde daraufhin als Unterschied etwa zum naturbeobachtenden Realismus des 19. Jahrhunderts festgestellt: Sie zeige noch keinerlei Phantasie-Leistung, sondern manifestiere allein ein vollkommen naiv nachahmendes Abbilden des in der Natur Gesehenen (wie es so nur zum Moment des absoluten Anfangs und ohne jede Vorgabe einer Bildtradition denkbar ist). ${ }^{34}$ Als wirkungsvollstes Argument, die prähistorischen Bildwerke aus dem Bereich der Kunstgeschichte zu entfremden, erwies sich aber die Funktionsfrage. Denn anstelle der ursprünglich favorisierten Erklärung als l'art pour l'art im Sinne eines spontanen Hervortretens eines allgemeinmenschlichen, spielerischen Kunsttriebs traten nun zunehmend Überlegungen, die diesen ersten Bildwerken Intention und Status von ,reiner Kunst' absprachen. Sie wurden nun vielmehr als eine Form von Bilderschrift (ein alter, bereits mit Blick auf die ägyptischen Hieroglyphen diskutierter Gedanke) oder aber und häufiger als Objekte

34 Marquis de Nadaillac: Die ersten Menschen und die prähistorischen Zeiten mit besonderer Berücksichtigung der Urbewohner Americas, hrsg. von W. Schlösser, E. Seler, Stuttgart 1884 (diese teils wesentlich umgearbeitete Übersetzung zieht zwei Bücher Nadaillacs zusammen: Les premiers hommes et les temps préhistoriques, Paris 1881, 2 Bde. und L'Amérique préhistorique, Paris 1883), S. 28: „Auch ist zu bemerken, dass diese Höhlenbewohner bei ihren künstlerischen Versuchen sich niemals von dem Spiel einer regellosen Phantasie hinreissen liessen, sondern sich im Gegentheil damit begnügten, einfach das zu kopieren, was sie vor Augen hatten." Die ,absolute Anfangssituation' der Steinzeit-Kunst, aber auch ihr scheinbares ,Ende' mit der radikalen Ablösung durch die geometrische Bildgestaltung ab der Bronzezeit faßt Salomon Reinach im abgewandelten Ovid-Zitat vom „proles sine matre creata, mater sine prole defuncta" zusammen (zit. nach H. Driesmans: Der Mensch der Urzeit, Stuttgart 1907, S. 33). - Vgl. dagegen etwa E. B. Tylor: Einleitung in das Studium der Anthropologie und Civilisation, Braunschweig 1883 [zuerst engl. 1881], S. 359-361: „Auch die beiden anderen schönen Künste, die Bildhauerkunst und die Malerei, haben ihren Ursprung in dem Einbildungsvermögen oder der Phantasie. Das, was der Künstler darstellen will, ist nicht die genaue Nachahmung eines Gegenstandes, sondern der Ausdruck einer Idee, welcher den Beschauer fesselt." 
der Bildmagie, ritueller und kultischer Praktiken verstanden - es ginge bei ihnen also gar nicht primär um Ästhetik, sondern um eine Botschaft oder wahrscheinlicher: um ihre Wirkkraft. ${ }^{35}$ Die sich hier abzeichnende Tendenz zur Ausgrenzung aus dem Bereich der ,Kunst ${ }^{\star}$ wurde schließlich noch dadurch verstärkt, daß selbst die wenigen Kunsthistoriker, die sich mit ,Kernfragen' des Faches beschäftigten und die Bedeutung der prähistorischen Kunstobjekte erkannten, es meistenteils versäumten, das neuen Material nachdrücklich in die Fach-Diskussion einzubringen. Selbst Alois Riegl, der zu Beginn seiner Stilfragen 1893 auf neun Seiten (bezeichnenderweise jedoch im Kapitel „Der geometrische Stil“) die Erkenntnisse zu den Stein- und Knochen-Bildern der "Troglodyten" resümierte, wollte damit nur gegen die „technisch-materielle Entstehung der Künste“ à la Semper argumentieren, erklärte aber ansonsten diese „Kunsterzeugnisse als außerhalb des Rahmens seiner geschichtlichen Darstellung stehend“. ${ }^{36}$

35 Bilderschrift: K. von den Steinen: Unter den Naturvölkern Zentral-Brasiliens. Reiseschilderung und Ergebnisse der Zweiten Schingu-Expedition 1887-1888, Berlin 1894, Kap. XI ,Die Kunst ' (zit. ${ }^{2} 1897$, S. 230-265); É. Piette: Les galets colories du Masd'Azil, in: L'Antbropologie, 7, 1896, S. 385-427. - Apotropäische oder beschwörende Bildmagie, wie sie v.a. im Gefolge der Arbeiten von J.G. Frazer (Totemism, 1887; Golden Bough, ab 1890) sowie H. Hubert und M. Mauss (Théorie générale de la Magie, 1902-03) entstanden: S. Reinach: L'art et la magie à propos des peintures et des gravures de l'âge du renne, in: L'Antbropologie, 14, 1903, S. 257-266; E. Löwy: Ursprünge der bildenden Kunst, in: Akademie der Wissenschaften in Wien. Almanach für das Jahr 1930, 80, 1930, S. 275-295 und dann ab 1930 v. a. die Arbeiten von M. Raphael, Prähistorische Höhlenmalerei. Aufsätze - Briefe, hrsg. von W. E. Drewes, Köln 1993. - Analysierend J. Halverson: Art for Art's Sake in the Paleolithic, in: Current Antbropology, 28, 1987, S. 63-89; N. Richard: De l'art ludique à l'art magique. Interprétations de l'art parietal au XIX ${ }^{\mathrm{e}}$ siècle, in: Bulletin de la Société Prébistorique Française, 90/1-2, 1993, S. 60-68; M. Weissl: Löwys These von den Ursprüngen der bildenden Kunst, in: F. Brein ( $\mathrm{Hg}$ ): Emanuel Löwy - ein vergessener Pionier (Kataloge der Archäologischen Sammlung der Universität Wien, Sonderbeft 1), Wien 1998; R. White: Prebistoric Art. The symbolic journey of bumankind, New York 2003, S. 20-61; zur Vorgeschichte apotropäischer Bilddeutung R. Schlesier: Kulte, Mythen und Gelehrte. Anthropologie der Antike seit 1800, Frankfurt a.M. 1994, S. $42-61$.

36 A. Riegl: Stilfragen. Grundlegungen zu einer Geschichte der Ornamentik, Wien 1893 , S. $16-24$. 


\section{Erste Bilder von ersten Künstlern}

Es gab freilich noch andere Möglichkeiten, Entstehung und Wesen dieser neuartigen ,ersten Kunstwerke' konzeptuell an bisherige gängige Vorstellungen ,anschlußfähig' zu machen - auf visueller Ebene nämlich. Wie dies geschah, kann die wohl früheste graphische Rekonstruktion einer Gruppe von Urzeit-Künstlern durch Émile Bayard demonstrieren. Die Illustration war als Holzstich dem sehr erfolgreichen Buch Louis Figuiers: L'homme primitif, beigefügt, das zwischen 1870 und Anfang der 1880er Jahre fünf französische Auflagen und zudem Übersetzungen ins Englische und Italienische durchlief: Begleitet von der Bildunterschrift „Die Vorläufer Raffaels und Michelangelos, oder: Die Geburt der Künste der Zeichnung und Skulptur im Rentier-Zeitalter" sieht man drei Männer in Felslandschaft, von denen der vorderste sitzend die Zeichnung eines Rentiers oder Hirsches in ein kleines Knochenstück einritzt, dahinter scheint ein zweiter Künstler ein weiteres Rentier aus Ton (?) zu modellieren - zumindest spricht seine Handhaltung mehr für Modellierstab denn Schnitzmesser -, schließlich kratzt ein dritter (wie an einer Staffelei stehend) ein weiteres Rentier in Umrißlinien auf ein Stück glatten Steins, das in Augenhöhe an einer Felswand aufgestellt ist (Abb. 4). ${ }^{37}$ Die Abbildungen auf der vorausgehenden und nachfolgenden Seiten zeigen entsprechende, tatsächliche

37 L. Figuier: L'homme primitif, Paris 1870, S. 131, fig. 67, zur Kunst S. 126-136; diese Tafel - wie viele andere von Bayard/Figuier auch - wiederverwendet in Baer [wie Anm. 27]; s. C. Blanckaert: Les bases de la civilisation. Lectures de l'homme primitif de Louis Figuier (1870), in: Bulletin de la Société Préhistorique Française, 90, 1993, S. 31-49. - Zur Erfindung des prähistorischen „Tafelbildes“ vgl. É. Piette: L'art pendant l'âge du renne: la question de la domestication des animaux, in: Compte-rendue, Congrès Internationale Anthropologique X, Paris 1889, S. 159-161 und 167171, hier S. 159 f., und das Zitat daraus bei Hoernes [wie Anm. 10], S. 41. - Zur ,Bildgeschichte des Urmenschen' S. Moser: Ancestral Images. The Iconography of Human Origins, Ithaca (NY) 1998; Venus et Cain [wie Anm. 1]; M. P. Gindhart: A pinacothèque prébistorique for the Musée des Antiquités Nationales in Saint-Germain-en-Laye, in: Journal of the History of Collections, 19, 2007, S. 51-74 (alle mit weiterer Lit.). 
Fundstücke von Tierknochen und Steinplatten mit Ritzzeichnung (allerdings keine beweglichen Tonplastiken ${ }^{38}$ ), die in Verbindung mit den zugehörigen Erläuterungen der rekonstruierten Szene historische Wahrscheinlichkeit verleihen sollen, die ihrerseits im Text mit keinem Wort kommentiert wird. Wichtige Anregung für diese Visualisierung des absoluten Ursprungs der Kunst und mit großer Wahrscheinlichkeit auch Referenzhorizont für einen Gutteil der zeitgenössischen Betrachter scheint dabei die einzige Themenstellung gewesen zu sein, bei der schon zuvor ein halbwegs vergleichbarer , primitiver Anfang' der Kunst verbildlicht worden war: also nicht eine der mythischen Erfindergestalten (Tocher des Dibutades usw.), sondern die legendäre Entdeckung des kleinen Ziegenhirten Giotto beim Abzeichnen seiner Tiere durch Cimabue. In diesem spätestens seit Vasaris Viten allgemein bekannten und in der französischen Kunst des 19. Jahrhunderts mehrfach dargestellten Beispiel geht es ebenfalls um eine angeborene, wenngleich außergewöhnliche mimetische Begabung ohne Ausbildung, die zu einem, (Neu-)Anfang' der Kunst führte (Abb. 5). ${ }^{39}$ Entsprechend erscheint nun das Tun der Urzeit-Maler und -Skulpteure als, Kindheit der Kunst ${ }^{`}$ und als instinktiver mimetischer Impuls, der zu erstaunlichen, wenngleich noch zu keinen künstlerisch vollgültig durchgearbeiteten Produkten führte. (Die seit Aristoteles kursierende und etwa von Winckelmann prominent aufgegriffene Vorstellung vom angeborenen Nachahmungs-Trieb, der sich gleichermaßen, wenn nicht sogar zuerst im Modellieren zeigt, scheint primär auch für die Darstellung des Tonplastikers verantwortlich neue prähistorische Funde und ethnographische Beobachtungen, die auf ein tatsächlich höheres Alter plastischer Kunst zu deuten schienen, wurden dagegen erst einige Jahre später gemacht. ${ }^{40}$ ). Schließlich könnte auch die

38 Aus Lehm am Boden modellierte Tiere in der Höhle von Tuc d'Audoubert und in der Höhle von Montespan wurden erst später gefunden.

39 P. Goergel, A.-M. Lecoq: La peinture dans la peinture, Dijon 1982, S. 127; U. Pfisterer: Erste Werke und Autopoiesis, in: ders., M. Seidel (Hg.): Visuelle Topoi. Erfindung und tradiertes Wissen in den Künsten der Renaissance, München/Berlin 2003, S. 263-302, hier S. 264-267.

40 Aristoteles: Poetik, 1448b; Philostrat: Leben des Apollonius von Tyana, II, 22; J.J. Winckelmann: Geschichte der Kunst des Altertbums, Dresden 1764, S. 4. - Hoernes 
Bildunterschrift programmatisch zu verstehen sein, stellt sie doch noch eine weitere, zunächst überraschende und enge Verbindung zwischen den Urzeit-Künstlern und dem Höhepunkt der Kunst unter Michelangelo und Raffael her, wogegen Figuiers Leser zunächst doch wohl viel eher ihre eigene Malerei und Skulptur (teils im Stil der Neo-Renaissance) in Bezug zur Hochrenaissance gesehen haben dürften. Allerdings regten sich in den Jahren unmittelbar vor Publikation des L'homme primitif 1870 Stimmen, die unter dem Schlagwort der nä̈veté stellvertretend Michelangelos Werke positiv mit denen von ,Primitiven', mit einheimischer Volkskunst und mit Kinderzeichnungen verglichen - im Sinne einer, echten', unmittelbar empfundenen Kunst-Äußerung. Dagegen wurde die historistische ,HochKunst' des 19. Jahrhunderts für ihre reflektierte Künstlichkeit getadelt und unter anderem ein neuer, einfach-naturalistischer 'Malstil à la Courbet verteidigt. ${ }^{41}$ Die Aussage unserer Illustration läßt sich also wohl noch dahingehend präzisieren, daß die prähistorische Bildnerei zwar künstlerisch noch in ihren Anfängen stecken mochte, der künstlerische Impuls der Urzeit-Menschen als solcher aber aus tiefstem Wesensinneren kam, voll entwickelt, hochbedeutsam und damit dem Schaffen Raffaels und Michelangelos aufs engste vergleichbar war.

[wie Anm. 10], S. 49: „Der Hauptwerth der Höhlenforschungen Piette's beruht auf dem Nachweise, dass am Anfange der bildkünstlerischen Entwicklung, wenigstens an einem Punkte [...], nicht das geometrische Ornament, nicht die naturalistische Thierzeichnung, nicht einmal die rundgebildete Thierfigur, sondern die plastisch ausgeführte Menschenfigur zu finden ist"; Riegl [wie Anm. 36], S. 1 f.; K. von den Steinen [wie Anm. 35], S. 251: „Die Kunst der Indianer, körperliche Formen nachzuahmen, ist ungleich weiter fortgeschritten als die der Zeichnung."

41 Zu Michelangelo und Kinderzeichnungen R. Töpffer: Réflexions et menus-propos d'un peintre Génevois ..., Paris 1848, S. 254 f.; zu Volkskunst, , Wilden' und Michelangelo Champfleury (J. Fleury): Histoire de l'Imagerie Populaire, Paris 1869, S. xii; diese Quellen und die Relevanz für Courbet behandelt M. Schapiro: Courbet and Popular Imagery. An Essay on Realism and Naïveté, in: Journal of the Warburg and Courtauld Institutes, 4, 1941/42, S. 164-191; vgl. auch Küster [wie Anm. 1], S. 5677. - Noch das Titelblatt zu Bölsche [wie Anm. 26] zeigt einen prähistorischen ,Schnitz-Künstler' vor dem Moses Michelangelos. 
Überraschenderweise wurde in der zweiten, bereits Ende 1870 erschienenen und grundlegend überarbeiteten Ausgabe von Figuiers Werk dann just diese offenbar so intensiv konzipierte Künstler-Episode ans Ende des Buches verschoben (als fig. 226 stand sie nun für „Les arts du dessin et de la sculpture à l'époque du bronze"). Die anstelle dessen neu eingefügte Szenerie des ,Anfangs der Künste' präsentiert sich tiefgreifend verwandelt (Abb. 6). Man glaubt sich auf den ersten Blick in eine sommerliche Polaroder Tundra-Landschaft mit Zelt und drei Eskimos versetzt, von denen der vorderste und prominenteste Werkzeuge, insbesondere Nadeln, aus Rentier-Geweih fertigt, dahinter modelliert ein weiterer Bewohner ein kleines freistehendes Rentier aus immer noch nicht genauer bestimmbarem Material, im Hintergrund blicken wir schließlich einem in Pelz Gehüllten über die Schulter, der eine Steinplatte mit Ritzungen versieht - eine bereits vollendete Steinplatte mit der Zeichnung eines Urpferdes ist zudem ganz im Vordergrund abgelegt. Dieser Austausch geht auf das Bestreben zurück, die Illustration zu, verwissenschaftlichen': Der Giotto-Bezug und damit die zu augenfälligen topischen und a-historischen Vorstellungen vom angeborenen Nachahmungstrieb der Menschen in der ersten Auflage wurden ersetzt durch eine hochaktuelle, ethnographische Parallele' zu zeitgenössischen ,Primitiven' der Polargegenden, deren Lebensumstände der damaligen Spät- und Nach-Eiszeit und deren bildnerischen Versuchen im „rohen Eskimostyl" der Urzeit-Kunst am nächsten zu kommen schienen - ein Vergleich, den Figuier selbst im Vorwort als Grund für die radikale Umarbeitung seines Buches nennt und der sich just in den frühen 1870er Jahren allgemein etablierte, allerdings insofern kontrovers diskutiert wurde, als einige Forscher die Parallele nur als Analogie verstanden, andere dagegen die Polarvölker als tatsächliche Nachfahren der Urmenschen verstanden. ${ }^{42}$

42 Ausschlaggebend für Figuier, der bereits in der Erstausgabe 1870, S. 111 mit einem Satz auf die ähnlichen Näh-Werkzeuge der Lappen hinweist, war nach eigener Aussage die Publikation von F. Pruner-Bey: Anthropologie de Solutré, Macon 1869 (dazu A. Roussot: Aryen ou Lapon? L'homme primitif vu par Louis Figuier en 1870, in: Venus et Caïn [wie Anm. 1], S. 76-83). Für die Visualisierung der, ersten Künstler' dürften jedoch zwei andere Publikationen entscheidende Anregungen gegeben haben: einerseits Lartet, Christy [wie Anm. 8], S. 127-141, die den Vergleich 


\section{Wieder liefert Karl Kraus alias Carus Sterne eine konzise Zusammenfas- sung:}

„[Man] findet [...] glücklicherweise in der Jetztzeit einige Menschenstämme, welche in ganz ähnlicher Weise ihre Waffen und Geräthschaften gerne mit derartigen, der heimischen Tierwelt entlehnten figürlichen Ornamenten verzieren, wie es die Bewohner Südfrankreichs und Mitteleuropas zur Renthierzeit zu thun gewöhnt waren. Von ihnen sind die Eskimos die wichtigsten, weil sie nicht nur in Gegenden wohnen, die heute ein ähnliches Klima haben, wie Mitteleuropa in den in Rede stehenden Zeiten, sondern auch in ähnlicher Weise ausschließlich von Jagd und Fischfang leben, wie jene Menschen der älteren Steinzeit, ja sogar gewisse thierische Vorbilder für ihren Kunsttrieb mit denselben gemein haben, wie z. B. das Renthier, den Moschusochsen, Bären u.a. Wir können also [...] die beiderseitigen Leistungen unmittelbar miteinander vergleichen, und dabei stellt sich dann eine so große Ähnlichkeit und Uebereinstimmung heraus, daß einzelne Forscher gemeint haben, die Renthier-Franzosen müßten demselben Stamme angehört

hinsichtlich des gemeinsamen Gebrauchs von Beinnadeln, wie sie in Figuiers Abbildung im Zentrum gefertigt werden, nur im Sinne einer Analogie verstanden, und andererseits Hamy [wie Anm. 25], S. 355-367, der mit aller Vorsicht tatsächliche Verbindungen sieht und u. a. auf den Kunststil und speziell die naturnahen Ritzzeichnungen von Tieren verweist; möglicherweise auch wichtig M.E. Dupont, Les temps préhistoriques en Belgique. L'bomme pendant les âges de la pierre dans les environs de Dinant-Sur-Meuse, Brüssel 21872, S. 81, S. 93 f., 142 f. und 186 f., den Figuier in anderem Zusammenhang wenig später zitiert. - Vgl. allerdings schon die Bemerkung von Fraas [wie Anm. 8], S. 465: „Besondere Erwähnung verdienen endlich die Kunstwerke auf Rennthiergeweihen, gleichfalls von Langerie-basse. Fünf Stück sind $[\ldots]$ vorgelegt worden, mit den erkennbaren Reliefs von Stier (Auerochs), Esel oder Pferd, Rennthier, Hirsch und Fisch, Arbeiten, die etwa an den rohen Eskimostyl erinnern." Bei Baer [wie Anm. 27], S. 146-151 Abbildungen von gut vergleichbaren Tierskulpturen aus Sibirien; Parallelen zu Bildwerken von den Aleuten und der Buschmänner bei Ratzel [wie Anm. 33], S. 72. - Eine forschungsgeschichtliche Zusammenfassung der in den Jahrzehnten um 1900 entwickelten Theorien, die die Kunst der Eskimos als nächste Parallele und teils direkte Nachkommen paläolithischer Bildnerei sahen, bei F. de Laguna: A Comparison of Eskimo and Paleolithic Art, in: American Journal of Archeology, 36, 1932, S. 477-511, hier v. a. S. 478-481, und 37, 1933, S. 77-107, allerdings mit lückenhafter Literatur-Kenntnis, so daß de Laguna als einzigen Ausgangspunkt dieses Vergleichs W. Boyd Dawkins: Esquimaux in the South of Gaul, in: Saturday Review, 6. Dez., London 1866 anführt, obwohl er sich neben den deutschsprachigen Beiträgen etwa bereits prominent 1862 bei Wilson [wie Anm. 24], S. 44 und 341-343 findet. 
haben, gewissermaßen selbst Eskimos gewesen sein. [...] Allein die neuere Forschung hat ergeben, daß die Annahme der alten turanisch-mongolischen Bevölkerung Europas auf falschen Voraussetzungen und Schlüssen beruhte, daß Europa seit den ältesten Zeiten von hochgewachsenen arischen Stämmmen bewohnt gewesen ist, [...]. Dagegen glichen die Renthierfranzosen [...] in ihrer Kulturstufe und Lebensweise letzteren [den ,Eskimos'] so vollkommen, daß sich daraus die Aehnlichkeit der Aeußerungen ihres beiderseitigen Kunstrriebs völlig befriedigend erklärt. “43

Insgesamt bleibt jedoch für alle Auflagen von Figuiers Entwicklungsgeschichte des fossilen Menschen die ,Semper-Doktrin' insofern wirksam, als die ,zweckfreien' Künste der Zeichnung und Skulptur erst am Übergang zur zweiten Kulturphase, eben der „Époque du renne“, auftreten (gleichzeitig mit den Anfängen des Hausbaus), wogegen die aus der Notwendigkeit geborene, ,nützliche Kunst des Töpferns angeblich bereits in der vorausgehenden "Epoche des großen Höhlenbären“ erfunden worden war (neben der Stein- und Knochenbearbeitung und der Herstellung von Schmuck) (Abb. 7). ${ }^{44}$ Nochmals ganz deutlich wird an dieser Beispielreihe auch, in welchem Maße selbst bei Darstellungen, die dem archäologischen Befund verpflichtet sind und diesen in Text und Bild zur Authentifizierung heranziehen, spekulative Theorien und Mythen wirkmächtig blieben.

Die nächstfolgenden Verbildlichungen prähistorischer Künstler auf der Pariser Weltausstellung von 1889 müssen an dieser Stelle übergangen werden, ihre Bedeutung wird erst im letzten Kapitel deutlich. Aufschlußreich scheint dagegen der Vergleich zweier kurz nach 1900 im Abstand weniger

43 Sterne [wie Anm. 16], S. 142 f.

44 Figuier [wie Anm. 37], S. 57, fig. 17 „Le premier potier", und der Kommentar im Geiste Sempers, allerdings um den ausgrabungsarchäologischen ,Beweis' ergänzt, S. 55 f. - Diese Entwicklungslogik sorgt offenbar auch dafür, daß Figuier die Steinritzzeichnung eines Höhlenbären (S. 84f., fig. 36), die als am Ende der Höhlenbären-Epoche entstanden galt, nicht als den eigentlichen Beginn der Bildkünste herausstellt, sondern als singulären Vorläufer, wegerklärt'; den Hausbau sieht Figuier dagegen anders als Semper erst in der Rentier-Zeit verwirklicht, vgl. S. 103, fig. 40 "Vue de l'abri sous roche de Bruniquel, habitation de l'homme à l'époque du renne“. - Eine kurze Zusammenfassung des frühen Streits und der Argumente um die Datierung der ersten Töpferprodukte, die etwa Mortillet und Cartailhac (zurecht) erst in die Jungsteinzeit datieren wollten, gibt Joly [wie Anm. 33], S. 364-373. 
Jahre erschienener Titelbilder zu populären Büchern über die Vorzeit, beide zeigen frühe Rekonstruktionen von Höhlenmalern bei der Arbeit: das erste gehört zu Wilhelm Bölsches 1909 publiziertem, erstem Band von Der Mensch der Vorzeit, das andere, ein zweifarbiger Holzschnitt in Schwarz und Rot, ziert Friedrich Behns schmales Heft Der Mensch der Urzeit von 1913 (Abb. 8, 9). ${ }^{45}$ Bölsches, naturalistische $e^{6}$ Illustration basiert noch ganz auf der Vorstellung von prähistorischer Kunst als l'art pour l'art, indem sie das staunend-freudige Interesse einer Höhlen bewohnenden (?) Sippe an den Bildschöpfungen ihres künstlerisch begabten Mitgliedes entwirft. Auch bei Behn dürfte das Rentier in Rot an der Felswand wohl nicht als Ritzzeichnung, sondern tatsächlich als farbige Malerei zu verstehen sein wie der nachfolgende Text dann erläutert: „Zu alles überragender Höhe aber erhebt sich das Können der Künstler, die in den Höhlen der Pyrenäen, in Marsulas ủnd Altamira, [...] zeichneten und malten" (allerdings fand sich für Behn das „beste Abbild“ gerade eines Rentiers, das zudem ,an der Spitze aller Tierdarstellungen der Zeit [steht], was gewissenhafte Sorgfalt und Feinheit der Ausführung betrifft", in ein Geweihstück eingeritzt). ${ }^{46}$ Vor allem aber treffen in diesem Holzschnitt der „starke, echte Naturalismus [der Vorzeitkunst], der in unbewußter, selbstverständlicher Treue und Sachlichkeit seine Werke schuf" zusammen mit einem modernen Illustrationsstil, der Elemente der neuartigen expressionistischen Vereinfachung aufgreift. ${ }^{47}$ Behns Titelbild spannt so wohl weniger aus seiner zeitgenössisch-bewußten Konzeption heraus denn aus unserer Perspektive sinnbildhaft die polaren Gegensätze von ,Einfühlung' und ,Abstraktion' auf, wie sie Wilhelm Worringer in seiner Dissertation von 1907 als Grundprinzipien aller bildkünstlerischen Produktion entwickelt hatte und wie sie mit ungeheurer Resonanz die Diskussionen der nächsten Jahrzehnte bestimmen

45 W. Bölsche: Der Mensch der Urzeit. I. Tertiärzeit E Diluvium, Stuttgart 1909; Behn [wie Anm. 16]. - Nicht im Druck erschienen, sondern als Ölgemälde bereits Paul Jamin: Peintre décorateur à l'âge de pierre, 1903, Privatslg. Paris; vgl. Venus et Caïn [wie Anm. 1], S. 93.

46 Behn [wie Anm. 16], S. 36-38.

47 Das Zitat ebd., S. 30. 
sollten. ${ }^{48}$ Dabei schien speziell auch die ,Kunstgeschichte der Vorzeit" archetypisch diesem konzeptionellem Antagonismus zu folgen: Denn zugespitzt formuliert - folgte auf den ,reinen Einfühlungs-Naturalismus" des Paläolithikums, wie ihn Altamira idealtypisch vor Augen führte, die ebenso ,absolute ornamentale Abstraktion' der Bronze- und Eisenzeit. Ja, dieser Gegensatz in der Entwicklung künstlerischen Gestaltens vorgeschichtlicher Kulturen war so augenfällig, daß er eigentlich schon längst vor Worringer erkannt war: Bereits Alexander Conze (1871), Alois Riegl (1893), Ernst Grosse (1894) oder Karl von den Steinen (1894) unterschieden naturnachahmende und geometrische Gestaltungsprinzipien, wobei insbesondere Grosse den Unterschied zwischen dem naturhaftem Stil der Jägervölker und dem geometrischen der Ackerbauvölker aus den verschiedenen Wirtschafts- und daraus resultierenden Kulturformen zu erklären versucht. ${ }^{49}$ Und ein Jahr vor Worringer (und dann noch mehrfach in Vorträgen und Publikationen) prägte der Göttinger Mediziner Max Verworn, der die „psychologischen Wurzeln der Kunst“ in der Urzeit, bei den ,Primitiven" und bei Kindern erforschte, für diese Form-Alternativen gar das Begriffspaar „physioplastisches" und „ideoplastisches Gestalten“. ${ }^{50}$ Allein

48 W. Worringer: Abstraktion und Einfüblung. Ein Beitrag zur Stilpsychologie, München 1976; dazu S. K. Lang: Wilhelm Worringers Abstraktion und Einfühlung. Entstehung und Bedeutung, in: H. Böhringer, B. Söntgen (Hg.): Wilhelm Worringers Kunstgeschichte, München 2002, S. 81-117. - Die Bedeutung seiner Überlegungen für die prähistorische Kunst entwickelt Worringer dann ausführlicher in: Formprobleme der Gotik, München 1911, S. 12-19 zu „Augenbildern“ versus „Vorstellungsbildern".

49 K. von den Steinen [wie Anm. 35], S. 231; zu den anderen Autoren s. Anm. 24, 36, 92, 35 .

50 M. Verworn: Archäolithische und paläolithische Reisestudien in Frankreich und Portugal, in: Zeitschrift für Ethnologie, 4-5 (1906), S. 611-655; ders.: Kinderkunst und Urgeschichte, in: Sitzungsbericht des anthropologischen Vereins zu Göttingen vom 25. Jan. 1907, und in: Korrespondenzblatt der Deutschen Gesellschaft für Anthropologie, Ethnologie und Urgeschichte, 37 (1907); ders.: Zur Psychologie der primitiven Kunst. Ein Vortrag, Jena 1908 [zuerst in der Naturwissenschaftlichen Wochenschrift, N.F. 6/44, 1907]; ders.: Die Anfänge der Kunst. Ein Vortrag, Jena 1909; ders.: Ideoplastische Kunst. Ein Vortrag, Jena 1914. 
Worringers für die gesamte Kunst postulierte Theorie und seine eingängigere Bezeichnung sollten diese spezifischeren Beiträge praktisch vollständig in den Hintergrund drängen. Bezeichnenderweise versuchten jedoch die Überblicksdarstellungen zur, primitiven Kunst' des einflußreichen Prähistorikers Herbert Kühn, der in der Kunstgeschichte mit einer Arbeit zu den „psychologischen Grundlagen des Stilwandels der modernen Kunst“ promoviert worden war (1918), nicht nur erneut eine eigene Terminologie einzuführen („sensorisch“ versus „,imaginativ“), sondern Kühn schloß seine Argumentation bevorzugt an Hauptvertreter der Kunstgeschichte: Riegl, Wölfflin, Worringer u.a. an, wogegen seine mit Blick auf die behandelten Objekte engeren ,Fachkollegen', etwa Verworn, häufig negativ beurteilt wurden. ${ }^{51}$ Spätestens mit Wilhelm Paulcke (1923) und Max Raphael (ab 1930) begann sich dann jedoch die Vorstellung durchzusetzen, daß der ,Primitivismus' prähistorischer Kunst nicht auf naives ,Abmalen', sondern ebenfalls auf das "Geistige in der Kunst“ ziele (so etwa bei den „Bisonten von Altamira"), daß er freilich grundlegend von dem der Moderne unterschieden sei - und mehr noch, daß es sich bei den steinzeitlichen Höhlenmalereien überhaupt nicht um eine, anfängliche noch eine ,primitive Kunstform handele. ${ }^{52}$

\section{Die typologische Methode und die Bedeutung der „Überlebsel“}

Mit jedem Anfang stellt sich das Problem der Fortsetzung und ihrer möglichen Beweggründe. Für die Anfänge der Kunst traf dies gleich in doppelter Hinsicht zu. Denn zum einen widersprach - wie gesehen - die Entwick-

51 Etwa H. Kühn: Primitive Kunst, in: M. Ebert (Hg.): Reallexikon der Vorgeschichte, Bd. 10, Berlin 1927/28, S. 264-292; Kühn [wie Anm. 8], etwa S. 210-235; zur Verbindung mit Worringer und dessen Einwände gegen Kühn s, auch H. Frank: Die mißverstandene Antithese. Zur logischen Struktur von Abstraktion und Einfühlung, in: Böhringer, Söntgen [wie Anm. 48], S. 67-80, hier v. a. S. 71 f.

52 W. Paulcke: Steinzeitkunst und moderne Kunst. Ein Vergleich, Stuttgart 1923, hier die Zitate S. 45 f.; Raphael [wie Anm. 35], etwa S. 11 und 15. 
lung nach Ausweis der neuen Funde allen bisherigen Annahmen: weder Ornament noch Töpferei noch Architektur, sondern die Bildkünste der Malerei und Plastik markierten den Anfang menschlicher Kunsttätigkeit, und auf den sensorischen oder physioplastischen ,Naturalismus' der Steinzeit folgte die imaginative oder ideoplastische ,ornamentale Abstraktion der Bronzezeit. Zum anderen war innerhalb dieser Grobeinteilung über die Kunstobjekte selbst im einzelnen praktisch nichts bekannt, wodurch sie sich einer genaueren Entwicklungslinie hätten eingliedern lassen - weder Künstler, noch Entstehungszeit, noch Bedeutung. Man könnte meinen, dies beschreibe eine Normalsituation des Kunsthistorikers, der sich dauernd der Aufgabe gegenüber sieht, ,anonyme' Gegenstände in eine Reihenfolge und Entwicklungslogik zu bringen. Und tatsächlich erforderten zwei der zentralen Problemstellungen des Faches auf dessen langem Weg zur modernen Wissenschaft vom frühen 19. bis zum frühen 20. Jahrhundert eine intensive Auseinandersetzung mit Formenreihen und ihren (internen) Sukzessionsmechanismen - nämlich sowohl die Frage nach der Datierung und Einordnung eines Werkes als auch die Frage von dessen Inhaltsdeutung. Letztere wurde bekanntlich von Aby Warburg und seinem Kreis um 1900 erprobt und dann 1923 von Erwin Panofsky festgeschrieben, wobei Warburg wie Panofsky mit sogenannten Typenreihen arbeiteten. Überraschenderweise fehlt aus dieser Zeit aber eine eingehende theoretische Auseinandersetzung der Kunstgeschichte mit diesem Problem. ${ }^{53}$ Im Folgenden soll gezeigt werden, daß auch für die Frage typologischer Entwicklungsreihen wiederum der Fall Altamira, stellvertretend zu verstehen für alle ,primitive', ,vor-historische' Kunst, wichtige Impulse lieferte. Die in Altamira emblematisch verdichtete Suche nach den ,Anfängen der Kunst ${ }^{c}$ führt so zu entscheidenden Fundierungen und Erweiterungen des methodischen Rüstzeugs der Disziplin Kunstgeschichte.

Erste ,kunsthistorische' Versuche, die Entwicklung von Kunstformen in ihrer Logik durch Reihenbildung möglichst exakt zu erfassen und durch

53 Eine Zusammenstellung bei U. Pfisterer, „Die Bilderwissenschaft ist mühelos" Topos, Typus und Pathosformel als methodische Herausforderung der Kunstgeschichte, in: Pfisterer, Seidel [wie Am. 39], S. 21-47. 
begleitende Serien von Illustrationen in den wichtigsten Stationen nachvollziehbar zu machen, finden sich im Jahrhundert zwischen William Hogarths Analysis of Beauty (1753) und John Ruskins Stones of Venice (1853). Unternimmt es jener noch, wenngleich mit Seitenblicken auf die geschichtliche Entwicklung, eine normative Ästhetik des Schönen festzuschreiben, so will dieser die Entwicklung des gotischen (Architektur-)Stils in Venedig erfassen, und zwar bis in jedes Detail der Profilierung hinein, oder besser gesagt: Ruskin will ausgehend von empirischen Einzelbefunden eine Entwicklungsgeschichte rekonstruieren, die Einzelelemente liefern ihm den "Schlüssel zum gesamten System der venezianischen Gotik“. ${ }^{54}$ So wichtig diese Stationen für die Kunstgeschichte sind: Im Vergleich zum methodischen Niveau von Klassifikationen und Reihenbildung der Naturwissenschaften und etwa auch der Inkunabel-Kunde muten diese Bemühungen noch relativ intuitiv, punktuell und teils simpel an. ${ }^{55}$

Dies ändert sich schlagartig mit den Untersuchungen von John Evans (1864/1875) zu den antiken Münzen der Briten, einer idealen Herausforderung für ein ,reihendes Ordnungsbestreben', sah sich der Forscher doch mit einer großen Zahl weitgehend undatierter Objekte konfrontiert. ${ }^{56}$ Und

54 Das Zitat und eine Analyse Ruskins und seiner Inspirationsquellen in der Architekturgeschichtsschreibung bei W. Kemp: John Ruskin. Leben und Werk, Frankfurt a. M. 1987, S. 149-161. - Bereits der Vorgeschichtsforscher Christian Jürgensen Thomson formulierte 1836/37 die Aufgabe, anhand von „angewandten Formen und Zierrathen " herauszubekommen, „in welcher Ordnung hiermit Veränderungen vorgegangen sind“, löste dies aber nicht ein; dazu Hansen [wie Anm. 29], S. 13.

55 A. Dickmann: Klassifikation - System - „scala naturae“. Das Ordnen der Objekte in Naturwissenschaften unf Pharmazie zwischen 1700 und 1850, Stuttgart 1992; F. A. Schmidt-Künsemüller: Ein früher typenmethodologischer Versuch in der Inkunabelkunde, in: S. Joost (Hg.): Bibliotheca Docet. Festgabe für Carl Webmer, Amsterdam 1963, S. 69-75 zur Bestimmung von Inkunablen durch den Naturforscher und Mainzer Bibliothekar Gotthelf Fischer von Waldheim, Beschreibung einiger typographischer Seltenheiten nebst Beyträgen zur Erfindungsgeschichte der Buchdruckerkunst, 1. Lfg., Mainz 1800.

56 J. Evans: The coins of the ancient Britons, 1864; ders., On the Coinage of the Ancient Britons and Natural Selection, in: Royal Institution of Great Britain. Proceedings, 7, 1875, S. 24-32; vgl. dann etwa H. Schurtz: Urgeschichte der Kultur, Leipzig/ Wien 1900, S. 4 f. 
sein Ergebnis stellte dann auch in zweifacher Hinsicht einen Wendepunkt dar: Anhand der Münzen (und durch Tafeln illustriert) ließ sich nicht nur nachweisen, wie antike Vorbilder (etwa ein Pferdegespann Philipps von Makedonien) im Laufe der Zeit und durch immer wieder kopierende Überlieferung formal vollkommen entstellt und zu Bildchiffren ,abstrahiert' wurden, in diesem Fall also keine ,Höher-Entwicklung', sondern eine ,Degeneration" vorlag (Abb. 10). Es zeichnete sich auch ab, daß parallel dazu ursprüngliche Bedeutungen von Bildern verloren gehen konnten oder sich einschneidend veränderten. Ergänzt und erweitert wurden diesen Erkenntnisse durch die survival-Theorie des Kultur-Anthropologen und Vorgeschichtsforschers Edward B. Tylor, die in Anlehnung an biologische Evolutionsvorstellungen das Tradieren eigentlich überflüssig gewordener Elemente als Charakteristikum menschlicher Kulturentwicklung und zugleich die interpretatorische Bedeutung dieser „Überlebsel“ für die moderne Forschung erkannte, wobei Tylor vorgeschichtliche und ,primitive Völker gleichermaßen die Argumente lieferten. ${ }^{57}$

Explizit auf dieser Grundlage - Evans, Tylor und den Evolutionstheorien Darwins und Spencers - entwickelten dann gleich zwei Prähistoriker zeitgleich und unabhängig voneinander die ersten methodisch konsequent durchdachten Programme typologischer Reihenbildung. Der englische Offizier und Privatgelehrte Augustus Henry Lane Fox Pitt Rivers stellte seine Erkenntnisse ab den späten $1860 \mathrm{er}$ in einigen Aufsätzen, vor allem jedoch in der Hängung seiner Privatsammlung, die er 1883 großenteils an die Universität Oxford stiftete, vor. ${ }^{58}$ Ausgehend von der Erkenntnis, daß sich in

57 Am prominentesten dargelegt in E.B. Tylor: Primitive Culture, London 1871, 2 Bde., hier etwa Bd. 1, S. $68 \mathrm{ff}$; dazu M. T. Hodgen: The Doctrine of Survivals. A chapter in the history of scientific method in the study of man, London 1935.

58 A. H. Lane Fox Pitt Rivers: The Evolution of Culture and Other Essays, hrsg. von J. L. Myres, Oxford 1906, S. 1-19 und 20-44 - Zu Pitt Rivers Methode, Museumsordnung und dem größeren Kontext vgl. B. Blackwood: The classification of artefacts in the Pitt Rivers Museum Oxford, Oxford 1970; D. K. van Keuren: Museums and Ideology: Augustus Pitt Rivers, anthropological museums, and social change in later Victorian Britain, in: Victorian Studies, 28, 1984, S. 171-189; N. Dias: Musée d'ethnographie du Trocadéro (1878-1908). Antbropologie et muséologie en France, 
der Entwicklung von Waffen Verbesserungen und Fortschritt in kleinsten Schritten manifestierten, untersuchte Pitt Rivers diese evolutionären Mechanismen nicht nur für verschiedenste Bereiche der materiellen Kultur, darunter der Kunst und Ornamentik, sondern konnte damit auch komplexe Prozesse der formalen Überlagerung und Beeinflussung durch andere Kulturkreise erklären:

"It [typology] supplies the want of dates by showing how certain forms must have preceded or followed others in the order of their development, or in the sequence of their adoption. It may be said, as a rule, that simple forms have preceded complex ones. Within certain limits this must be true, but it is not always the case, for, in many instances, progress consists in eliminating superfluous complexity, and reducing the expenditure of time and labour [...] It is the work of typology to unravel the true thread of events, and place the objects in their proper sequence [...]. Typology forms a tree of progress, and distinguishes the leading shoots from the minor branches." 59

Allerdings erreichen die wenigen Abbildungen zu Pitt Rivers grundlegenden Aufsätzen nicht das visuelle ,Argumentations-Niveau' der Tafeln von Evans, von denen Pitt Rivers eine reproduziert: Beschränken sie sich doch etwa bei der Darstellung verschiedener Paddel-Formen des Pazifiks - auf einige wenige Objekte, die stellvertretend für erreichte Hauptstufen stehen und gerade das zentrale Prinzip der langsamen und kleinteiligen Mutation und Beeinflussung nicht wiedergeben (Abb. 11). Die Anhänger von Pitt Rivers und einer auf die Kultur übertragenen Darwinschen Evolutionslehre, insbesondere Henry Balfour, Grant Allen, Alfred C. Haddon und Hjalmar Stolpe, sollten diese Ansätze in den Jahrzehnten bis $1900 \mathrm{zu}$ einèm umfassenden Theoriemodell für Kunst und Ornamentik weiterschreiben (unter Einbeziehung der neuen Wahrnehmungspsychologie) und so insbe-

Paris 1991. - Die Zusammenstellung etwa von australischen Bumerangs bei Klemm [wie Anm. 23], Bd. 1, Taf. VII a-g (kurze Erläuterungen S. 316 f.) könnten in ihrer Anordnung eine Anregung für Pitt Rivers gewesen sein; ebenso die eigenständigen Schriften Klemms zu Waffen und einem kulturgeschichtlichen Museumskonzept; vgl. auch Hildebrand [wie Anm. 23], S. 238 f.

59 A. H. Lane Fox Pitt Rivers: Typological Museums, as exemplified by the Pitt Rivers Museum in Oxford and his provincial museum in Farnham Dorset, in: Journal of the Society of Arts, 40, 1891, S. 115-22, hier S. 116. 
sondere auch die bis dato gültigen spekulativen ,Ornament-Grammatiken ablösen. ${ }^{60}$

Der zweite Vorgeschichtsforscher und Mitbegründer der Typologie war der Däne Oscar Montelius, wobei dessen Erkenntnisse wohl teilweise auch im Austausch mit seinem Kollegen Hans Hildebrand und dessen allerdings weniger nachdrücklich vorgetragenen Überlegungen entstanden. Montelius Theorien, deren Publikation in den späten 1870er Jahren einsetzte, kulminierte 1903 in einem Band zur Methode der Bestimmung der „älteren Kulturperioden im Orient und in Europa". Dabei ergaben sich die Prinizipen „absoluter" und „relativer" Chronologie materieller Zeugnisse aus der $\mathrm{Zu}$ sammenschau von stratigraphisch „sicherem Fund" und richtiger typologischer Zuordnung. Entwicklung und ,Überlebsel` verdeutlicht Montelius an den Beispielen des Übergangs von Postkutsche zu Eisenbahnwagen und der Stearinkerze zur elektrischen Lampe, da sowohl die frühen Eisenbahnwagen wie die Lampen funktional vollkommen nutzlose Gestaltungselemente ihrer Vorläufer, mitschleppten'. Prinzipell faßt Montelius zusammen:

„Die Ähnlichkeit zweier unmittelbar an einander stossender Glieder [der Typen-Reihe] kann oft so gross sein, dass ein ungeübtes Auge gar keinen Unterschied zwischen ihnen bemerken kann. Der erste und der letzte Typus der Serie sind aber gewöhnlich so unähnlich, dass dieser beim ersten Blick gar keine Verwandtschaft mit jenem zu haben scheint. [...] Eine besondere Aufmerksamkeit verdienen bei den typologischen Untersuchungen des Alterthumsforschers - eben so wie bei den entsprechenden des Naturforschers - die ,rudimentären' Bildungen: Theile des Gegenstandes, welche einmal eine Funktion hatten, allmählich aber ihre praktische Bedeutung verloren haben." ${ }^{11}$

$60 \mathrm{Zu}$ diesen Autoren Th. Munro: Evolution in the Arts and Other Theories of Culture History, Cleveland/New York 1964; ansatzweise bereits J. Ranke: Die Anfänge der Kunst. Anthropologische Beiträge zur Geschichte des Ornaments, Berlin 1879. Vgl. auch E. Black Jr.: Evolutionist Psychology and Aesthetics: the Cornhill Magazine 1875-1880, in: Journal of the History of Ideas, 45, 1984, S. 465-475.

61 O. Montelius: Die älteren Kulturperioden im Orient und in Europa. I. Die Methode, Stockholm 1903, S. 16f.; zu diesem Zeitpunkt kann Montelius seinerseits bereits Riegls Stilfragen erwähnen (S. 77, Anm. 1). - Vgl. auch H. Breuil: Exemples de figures dégénérées et stylisées à l'époque du Renne, in: Congrès international d'anthropologie et d'archéologie préhistorique ..., Monaco 1906, S. 1-12. 
Bei alledem gilt es zweierlei zu bedenken: Gar nicht bestritten sei, daß auf Seiten der Kunsthistoriker ähnliche Methodiken ebenfalls schon im späten 19. Jh. mit großem Erfolg in praxi Verwendung fanden, man denke nur an die "Feindatierungen" mittelalterlicher Ornamentik, Bauformen oder Gewandfalten etwa eines Wilhelm Pinder. Allerdings dürfte eben die hochkomplexe Vorstellung von "Kunst" (ihrer vielschichtigen ,Autonomie einerseits, ihrer Verbindung vielfältigster ,Einflüsse andererseits) verhindert haben, daß eine ähnlich stringente Theorie formuliert wurde, wie sie am vergleichsweise, simplen' prähistorischen Material zu entwickeln war. Bezeichnend scheint zudem, daß dann etwa August Schmarsow, der dieses Theoriedefizit um 1900 mit am deutlichsten wahrnahm, seine Beiträge dazu in expliziter Auseinandersetzung mit den Methoden der ,Völkerkunde entwickelte. ${ }^{62}$

Zudem waren diese Typenreihen, primitiver' Objekte und Kunstformen nicht ausschließlich, ja nicht einmal vorrangig zum Zweck der Datierung und Zuordnung angelegt. Ein solchermaßen rekonstruierter Entwicklungsverlauf einer Objektgruppe konservierte vielmehr ,Kräfte-Prozesse des menschlichen Geistes, wie sie bei allen vor-schriftlichen Kulturstufen überhaupt nur auf diesem Wege über die materiellen Relikte wissenschaftlich zu erfassen waren, dafür (wie man meinte) noch in besonders einfacher Klarheit und im Gegensatz zu den komplexen Überlagerungsformen bei Hochkulturen. Typenreihen waren sozusagen die Leitfossilien der geistigen Entwicklungen und Wesensstationen der Menschheit - ein bereits zeitgenössischer Vergleich, der auch nochmals an die zentrale Anregung dieser Methode durch die (freilich teils mißverstandenen, teils umgedeuteten) Theorien Darwins erinnert. Dabei wurde von vielen - voran Herbert Spencer - postuliert, die in den Typenreihen manifesten ,Kräfte-Prozesse ${ }^{6}$ des menschlichen Geistes und dessen langsame psychische Entwicklung (mit ihren ,Überlebseln') nicht nur in loser Analogie, sondern als mehr oder

62 A. Schmarsow: Kunstwissenschaft und Völkerpsychologie. Ein Versuch zur Verständigung, in: Zeitschrift für Ästhetik und Kunstwissenschaft, 2, 1907, S. 305-339 and 467-500; ders.: Anfangsgründe jeder Ornamentik, in: Zeitschrift für Ästhetik und Kunstwissenschaft, 5, 1910, S. 191-215 and 321-355. 
weniger tatsächliche evolutionäre Vererbungsmechanismen, die kulturelle Evolution als Fortsetzung der biologischen Phylogenese nach einigen wenigen, immer gleichen Grundprinzipen zu verstehen. Erworbene Eigenschaften könnten demnach teils als „Engramme“ in den vererbbaren, angeborenen Geistesbesitz der Menschheit eingehen, womit die evolutionäre Entwicklung bestimmter Kunstformen zwingend aus einer ,gemeinsamen reizphysiologischen Basis" aller Menschen erklärbar würde. ${ }^{63}$ In diesem großen Kontext jedenfalls wird auch die Bedeutung dieser Forschungen für Warburgs Theorien zu Nachleben und ,kulturellem Gedächtnis' unmittelbar evident - vielleicht am deutlichsten in den zusammenfassenden Formulierungen, die Heinrich Schurtz seiner im Jahr 1900 publizierten Urgeschichte der Kultur voranstellte. ${ }^{64}$ Insbesondere auch Warburgs Beobachtung von Polaritäts-Phänomenen, bei denen gleiche Kunstformen im Laufe der Zeit geradezu entgegengesetzte Bedeutungen absorbieren konnten, scheint Schurtz vorzubereiten mit seiner Erkenntnis des eingeborenen Umdeutungsbedürfnisses der Menschen bei gleichen Grundmotiven:

„Kunstwerke und vor allem Ornamente, deren Sinn nicht mehr verstanden wird, unterliegen leicht einer neuen Deutung. Die Neigung dazu liegt tief im Menschen begründet und äußert sich wohl auch zufälligen Schöpfungen der Natur gegenüber, an die sich erklärende Sagen knüpfen, und die man dann wohl noch künstlich weiterbildet; [...]. Blicken wir zurück auf die Arten und Werke der Kunst, so erkennen wir, daß ihnen bei aller spielenden Zwecklosigkeit zugleich etwas Schöpferisches innewohnt, und daß sie eine durch Wiederholung gebildete Form wie einen festen Panzer oder ein Knochengerüst besitzen. Das Spiel im eigentlichen Sinne hat diese Formhülle nicht und ebensowenig den schöpferischen Charakter der Kunst [...]. Im übrigen kann man das Spiel am besten eine Übung des Körpers oder des Geistes nennen, die wie die Kunst zunächst aus Kraftüberschüssen hervorgeht und keinen unmittelbaren Zweck hat." ${ }^{\text {"65 }}$

63 Die Zitate aus R. Semon: Die Mneme als erhaltendes Prinzip im Wechsel des organischen Geschehens, Leipzig 1904, der allerdings noch keinen direkten Bezug zur Kunst herstellt; dies unternimmt für die "Abstammung der Kunst" etwa Bölsche [wie Anm. 25], S. 27.

64 Schurtz [wie Anm. 56], S. 23 f.

65 Ebd., S. 550 f. - S. 544-546: „Kunststil“ durch Sinngebung sowie durch Stoff und Technik bedingt „Kümmer- oder Wucherformen“ im langen Kopier-Prozeß (nach Balfours Ornament-Untersuchungen). 
Der letzte hier interessierende Schritt der typologischen Methode ist spätestens 1929 mit dem Eintrag zu ,Typologie von Nils Åberg im Reallexikon der Vorgeschichte vollzogen. Nicht nur werden die Grundannahmen in fast karikierender Zuspitzung zusammengefaßt: „Die Typologie ist die Anwendung des Darwinismus auf die Produkte der menschlichen Arbeit. Sie geht von der Voraussetzung aus, daß der menschliche Wille an gewisse Gesetze gebunden sei, ähnlich denen, die für die Entwicklung in der organischen Welt Geltung haben. Die Altertümer entwickeln sich, als ob sie lebende Organismen wären, die einzelnen Gegenstände sind Individuen, eine Typenserie stellt die Entwicklung einer Art dar und eine Gruppe von Typenserien wiederum eine Entwicklung, die sich in verschiedene Arten verzweigt und eine Familie bildet." ${ }^{66}$ Åberg betont auch die prinzipielle Übertragbarkeit der Methode auf alle Epochen der Kunst- und Kulturgeschichte:

„Aber die Eigenart der typol. Methode bestand [...] nicht darin, lange Typenreihen aufzustellen, sondern das Leben in den Produkten seiner Arbeit zu studieren, und die Methode ist also auch auf höhere Kulturen anwendbar. Ein einfacher und primitiver Wille kann sich in langen Typenserien zum Ausdruck bringen, aber ein vielseitig wechselnder und komplizierter schafft sich in den Produkten seiner Arbeit einen ebenso komplizierten Ausdruck [...]. Moderne T. im Gegensatz zu vorgesch. oder primitiver besteht also nicht darin, gleich der letztgenannten Typenserien aufzustellen, sondern anstatt dessen etwa die Entwicklung vom romanischen zum frühgotischen Stil und zum „flamboyant“ zu verfolgen, [...]. Die Methode ist dieselbe wie früher, aber das Material ist unendlich komplizierter geworden. Es ist nicht mehr die Veränderung eines einzelnen Ornamentes oder eines anderen Details, das die Entwicklung charakterisiert, sondern es ist die Summierung oder, wenn man es so ausdrücken will, die mittlere Proportionale der Veränderungen einer Menge von verschiedenen Details. “ ${ }^{67}$

Vor diesem Hintergrund läßt sich nur spekulieren, warum die Kunstwissenschaft die typologische Methode nicht eingehender theoretisch reflektiert hat: Möglicherweise wurde sie um 1900 so selbstverständlich als Errungenschaft der Erforschung ,primitiver ${ }^{`}$ Objekte und Kunst angesehen,

66 N. Åberg, Typologie, in: M. Ebert (Hg.): Reallexikon der Vorgeschichte, Bd. 13, Berlin 1929, S. 508-516, hier S. 508.

67

Ebd., S. 514. 
seien sie frühgeschichtlicher, volkskundlicher oder ethnographischer $\mathrm{Na}$ tur, daß die Kunstgeschichte im engeren Sinne es gar nicht mehr für notwendig erachtete, sich damit weiter auseinander zu setzen? Und möglicherweise hat dann die Verdrängung des Problems Typenreihe teils auch damit zu tun, daß der Begriff ,Typus' zunehmend nicht nur formal, sondern auch im geistigen, rassischen und völkischen Sinn als Wesens- bzw. Menschen-Typus verstanden, diskutiert und schließlich mißbraucht wurde? ${ }^{68}$

\section{Prähistorische Künstlerinnen und der Ursprung weiblicher Ästhetik}

Auf der Pariser Weltausstellung von 1889 boten unter dem überragenden Schatten des neuen Weltwunders Eiffelturm selbst noch die historisch-didaktischen Abteilungen ihren Besuchern neuartige Sensationen: vor allem eine Serie von Dioramen, die über viele Jahrtausende hinweg realistische Einblicke in die Lebensumstände der Steinzeit-Menschen zu eröffnen vorgaben. Zwar waren prähistorische Funde bereits auf den beiden Vorgängerveranstaltungen in Paris 1878 und erstmals 1865/67 gezeigt und damit erst eigentlich allgemein bekannt gemacht worden: rund 50 Objekte vom Faustkeil bis hin zu den ,ersten Versuchen' der Menschheit im Medium Skulptur, allerdings nebeneinander aufgereiht in Glaskästen präsentiert. ${ }^{69}$ Und als nach Beendigung der Londoner Weltausstellung von 1851, der ersten ihrer

68 Neben dem Interesse an "Geistestypen“ etwa bei Dilthey, Weber und Simmel vgl. H. von Hollenhaag: Vom Typus in der Kunst, Leipzig/Wien 1905; O. A. Erich, Typenkunde und Kunstwissenschaft, in: Zeitschrift des deutschen Vereins für Kunstwissenschaft, 8, 1941, S. 239-244.

69 Vgl. Exposition de 1865. Palais de l'Industrie. Musée Rétrospectif, Paris 1867, S. 3: „Armes des ages de pierre et de bronze", und ausführlicher G. de Mortillet, Promenades préhistoriques à l'Exposition universelle. Abris de Bruniquel, in: Matériaux pour l'histoire positive e philosophique de l'bomme, 3, 1867, S. 201-203; Les Merveilles de l'Exposition de 1878, Paris 1878, S. 723 zu Beginn der „Exposition des arts rétrospectifs au Trocadéro“. - Vgl. auch Dias [wie Anm. 58]. 
Art überhaupt, die zentrale Glas-Eisen-Halle an anderem Ort als Crystal Palace und mit permanentem Ausstellungsprogramm wiederaufgebaut worden war, konnten bereits dort die Besucher ab 1854 spektakuläre lebensgroße Modelle von Dinosauriern, die sich in der Parklandschaft tummelten, bestaunen (wobei diese Urzeit-Tiere ebenfalls nur wenige Jahrzehnte zuvor wissenschaftlich entdeckt worden waren). ,Mannequins schließlich kamen bereits bei den früheren Weltausstellungen in Paris und ab 1884 im Musée du Trodacdéro zum Einsatz. ${ }^{70}$ Aber erst in Paris 1889 rekonstruierte man gleich an zwei Stellen Leben und Werk des homme fossile: So wurde der Themenpark zur geschichtlichen Entwicklung der „Habitation humaine" mit einer „Troglodyten-Höhle“ eröffnet. Vor allem aber nahm die „Histoire rétrospective du travail et des sciences anthropologiques" ihren Ausgang von mehreren Arrangements der Urzeit, plastischen Szenerien mit lebensgroßen Figuren, die den Menschen der Steinund dann auch der Bronzezeit in seiner ,natülichen', charakteristischen Umgebung darstellen sollten: ein Mann und eine Frau der "Mammutzeit" bearbeiteten Feuerstein (Abb. 12); im Eingangsbereich des Nachbaus einer Höhle aus dem Vézère-Tal stand das Oberhaupt einer Familie, ein bärtiger Mann, der gerade erfolgreich von der Bärenjagd zurückgekehrt war, wogegen ein junger Mann und eine junge Frau offenbar bei der Unterkunft geblieben und dort mit Tiergeweihen und Knochen beschäftig waren, die sie mit Bildgravuren versahen; die folgenden Szenen zeigten mit dem Bau einer Grabstätte (Dolmen) und dem Metallguß die weiteren entscheidenden Erfindungsschritte der Menschheit am Übergang zum Neolithikum bzw. zur Bronzezeit. ${ }^{71}$ Dabei erinnern insbesondere die Urmenschen der

70 M.J.S. Rudwick: Scenes from Deep Time. Early Pictorial Representations of the Prebistoric World, Chicago/London 1992, S. 140-150. - Für Mannequins vgl. Dias [wie Anm. 58], S. 167 und 188; S. Moser: The dilemma of didactic displays: habitat dioramas, life-groups and reconstructions of the past, in: N. Merriman (Hg.), Making Early Histories in Museums, London 1999, S. 95-116.

71 E. Monod: L'Exposition Universelle de 1889, Paris 1890, 3 Bde., hier Bd. 1, S. 158162 zur, Geschichte des menschlichen Wohnens'; S. 294 f. zu den Vorzeit-Dioramen; vgl. auch Les Merveilles de l'Exposition de 1889, Paris 1889, S. 161-214 und 
Mammutzeit nun nicht an Eskimos, sondern an australische Aborigines und nordamerikanische Indianer, deren Lebenweise ebenso häufig (und mindestens seit John Locke 1689) als ethnographische Parallele für die prähistorische Jägergesellschaft herangezogen wurde. ${ }^{72}$

So aufwendig diese Inszenierungen auch waren, prinzipiell unterschieden sie sich nicht von den Ansichten, wie sie bereits das Buch von Figuier von $1870 \mathrm{zu}$ den Entwicklungsstufen der Menschheit illustrierten - mit einer Ausnahme. Wenn auf den Abbildungen bei Figuier und seinen Kollegen überhaupt urzeitliche Frauen zu sehen waren, dann in ihrer (aus der Perspektive des 19. Jahrhunderts weithin) erwartungsgemäßen ,biologischen Rolle als Mütter und Hüterinnen der Heimstatt (Abb. 13, 14). ${ }^{73}$, Fortschritt ${ }^{6}$ in Form von Erfindungen und alle Arten aktiver Kunstfertigkeit waren dagegen männlich besetzt. ${ }^{74}$ Umso mehr erstaunt, daß in den Rekonstruktionen von 1889 zumindest aus der Stufe der Feuerstein-Bearbeitung und des Bildens in Tierknochen nun Frauen gleichberechtigt beteiligt erschie-

643-658. - Photographien dieser Gruppen publiziert M. Pilar San Augustin-Filaretos: Les influences respectives entre anthropologie et préhistoire, in: Venus et Caïn [wie Anm. 1], S. 54-59.

72 Etwa Wilson [wie Anm. 24]; Lartet, Christy [wie Anm. 8], S. 37-61; Nadaillac [wie Anm. 34]. - Vgl. Pilar San Augustin-Filaretos [wie Anm. 71].

73 Vgl. Boitard [wie Anm. 19], Frontispiz; Kupka entwarf die Vignetten für E. Réclus: L'Homme et la Terre, Paris 1905, hier Bd.1, S. 3. - Ausführliche Analysen bei D. Gifford-Gonzalez: You can hide, but you can't run: representations of women's work in illustrations of Paleolithic life, in: Visual Anthropology Review, 9/1, 1993, S.2341 und S. Moser: Gender stereotyping in pictorial reconstructions of human origins, in: H. du Cros, L. Smith (Hg.): Women in Archeology, Canberra 1993, S. 75-92.

74 Eine Differenzierung bei Caspari [wie Anm. 32], Bd. 2, S. 363: „Der Verlauf der Urgeschichte lehrt uns, daß sich schon sehr früh ein sogenannter arbeitender und kunsttreibender Stand in den primitiven urstaatlichen Gemeinden absonderte, ein Stand, der freilich ursprünglich sehr mißachtet und sklavisch behandelt wurde; denn zumeist waren es die zum herumtreibenden Jagdleben körperlich Untauglichen, welche sich mit Arbeit, beziehungsweise Kunstthätigkeit befassen mußten. Allein gerade dadurch, daß die kunstfertigen Arbeiter der Urzeit durch die Umstände mit Nothwendigkeit und Ausdauer auf ihr Geschäft hingewiesen waren, sammelten sich in ihnen die geistigen Kräfte." 
nen - erst die höheren Kunstübungen (Architektur und Metallbearbeitung) übernahmen dann wieder allein die Männer. Dem englischsprachigen Publikum mußte diese Gleichberechtigung aufgrund eines Seh- oder Erinnerungsfehlers noch überraschender erscheinen: Denn Thomas Wilson, der 1898 in den USA die erste übergreifende Geschichte der Vorzeit-Kunst publizierte - gleichzeitig und unabhängig von der ersten deutschsprachigen Veröffentlichung dieses Zuschnitts von Moritz Hörnes -, bildete die ersten beiden Diorama-Gruppen der Pariser Ausstellung von 1889 ab, mißverstand den jungen Mann vor der Höhle jedoch als zweite Frau, so daß bei ihm nun allein Frauen für die Bildschnitzereien auf den Gebeinen und damit für den absoluten Beginn der menschlichen Kunstübung zuständig waren (Abb. 15). Allerdings kommentieren seine Erläuterungen zu den Szenen die Relevanz dieser Rollenverteilung nicht. ${ }^{75}$ Es bleibt also die entscheidende Frage, warum am Ende des 19. Jahrhunderts plötzlich Frauen für die Anfänge der Kunst (mit-)verantwortlich zeichnen konnten?

Die Suche nach Antworten darauf in den zahlreichen Publikationen zur prähistorischen Kunst verläuft weitgehend erfolglos. Dagegen wird man überraschenderweise in einem Text des Mediziners und Anthropologen Rudolf Virchow Zur Geschichte des Kochens von 1876 fündig:

„[S]chon [...] ehe sie sich an den Heerd stellte, war die Frau wahrscheinlich überall die Hüterin des Feuers geworden. [...] Während der Mann noch in unruhiger Hast den Thieren des Waldes und der Steppe nachjagte [...], da schon senkten sich in ihre Brust die ersten Keime jener höheren Triebe, aus denen später das Kunstgewerbe hervorging. Sie fertigte die Kleider des Mannes und heftete daran allerlei farbigen Zierrathe, sie wob die Stoffe und fügte in dieselben zierliche Muster, sie entwickelte den Topf aus seiner ersten, rohen, flachen und niederen Form zu immer mehr plastischen Gestalten [...]. Von der Thonplastik ging dann später in den Händen der Männer die eigentliche Bildnerei aus. Aber ihr Anfang liegt am Heerde. Er gehört mit in die Geschichte des Kochens." 76

75 Wilson [wie Anm. 10], S. 417 und 373 f.; die Abb. nach Les merveilles de l'exposition de 1889 [wie Anm. 71], S. 644 f; auch W. G. Smith: Man the primeval savage, London 1894.

76 R. Virchow: Zur Geschichte des Kochens, in: Deutsche Rundschau, 3, 1876, das Zitat S. 279; zur Person C. Goschler: Rudolf Virchow: Mediziner, Anthropologe, 
Bereits Virchow legte also die höhere Kunstentwicklung in die Hände von Männern, die Anfänge der Künste jedoch, die er noch ganz in der Tradition Sempers und Conzes im Weben, der Schmuckherstellung und im Töpfern sah, entsprangen auch bei ihm einem weiblichen Impuls. Mit diesem Phantasieentwurf prähistorischer Rollen-Muster ist zwar noch keine Erklärung gegeben, es deuten sich jedoch die beiden Gedankentraditionen an, aus denen diese Vorstellung entstehen konnte: Zunächst einmal galt in der Antike und dann spätestens seit dem 15. Jahrhundert wieder die Beherrschung des Feuers als conditio sine qua non des zivilisatorischen Fortschritts der Menschheit. ${ }^{77}$ Wenn aber der Frau die Rolle einer Hüterin des Herdes seit Urzeiten ,natürlicherweise zufiel, dann mußte dieses RollenDenken des 19. Jahrhunderts paradoxerweise und quasi zwingend dazu führen, daß der kulturstiftende Einfluß des Feuers, zu dem die Frau einen früheren und intensiveren Kontakt hatte als der Mann, zuerst in ihr Wirkung zeitigte.

Damit aber nicht genug: Bei Virchow ist zudem von den „höheren Trieben" der Frau hin zur Kunst die Rede. So kritisch und distanziert sich der Berliner Wissenschaftler ansonsten gegenüber Darwins Evolutionslehren verhielt $^{78}$, hier scheint der Rekurs auf dessen nur fünf Jahre zuvor (1871)

Politiker, Köln u. a. 2002; die obige Passage auch bei D. Schmidt: Abfall und Vorgeschichte. Entdeckungen der Prähistorie im 19. Jahrhundert, in: K. Ebeling, S. Altekamp (Hg.): Die Aktualität des Archäologischen, Frankfurt a. M. 2004, S. 263-282.

77 Bereits L.B. Alberti: De re aedificatoria, 1, 2 konnte sich Vesta als Erfinderin des Hausbaus und damit der Baukunst insgesamt vorstellen; zusammenfassend Rykwert [wie Anm. 1], S. 105-118; vgl. dann etwa Klemm [wie Anm. 23], Bd. 1, S. 178 f. und 245 zum "Gebrauch des Feuers, das wir auch auf der niedrigsten Stufe der Cultur finden; [...] Das Entzünden des Feuers ist das erste, den Weibern [der, Waldindier'] obliegende Geschäft."

78 Ch. Andree: Rudolf Virchow als Prähistoriker, 2 Bde., Bonn 1976; A.W. Daum: Wissenschaftspopularisierung im 19. Jahrhundert: Bürgerliche Kultur, naturwissenschaftliche Bildung und die deutsche Öffentlichkeit, 1848-1914, Munich 1998; A. Zimmermann: Geschichtslose und schriftlose Völker in Spreeathen. Anthropologie als Kritik der Geschichtswissenschaft im Kaiserreich, in: Zeitschrift für Geschichtswissenschaft, 47, 1999, S. 197-210. 
publizierte Theorie von der „sexuellen Zuchtwahl“ nach ästhetischen Kriterien durch den weiblichen Part und die daraus resultierenden Entwicklungs-Mechanismen des „beauty for beauty's sake“ ziemlich eindeutig. Für Darwin war jedenfalls - so die populäre Kurzfassung seiner Theorie - „der Ursprung der Kunst in dem Sexualleben der Urmenschen zu suchen “. ${ }^{79}$ Nicht erst die soziale Rolle, sondern bereits das biologische Geschlecht prädestinierten die Frau also für die Wahrnehmung des Schönen, weshalb es für Virchow nur logisch erscheinen mußte, ihr auch die ersten Versuche auf dem Gebiet des Schmückens und Bildens zuzuweisen. Dagegen gestanden sich seine Kollegen diese Zusammenhänge kaum so explizit ein, negierten - wenn überhaupt - mit verschiedenen Gegenmodellen diese Konsequenz oder aber reagierten mit Ironie. Kaum anders denn ironisch läßt sich etwa 1879 der Hinweis von Nicolas Joly verstehen, ein Nachhall dieser besonders künstlerisch begabten urzeitlichen Menschenrasse des VézèreTals zeige sich noch in den Kunstprodukten neuzeitlicher Pariserinnen. ${ }^{80}$ Der Psychologe Collin Scott schlug dagegen eine derart modifizierte Evolutionstheorie vor, daß das männliche Geschlecht nicht weniger, sondern

79 Ch. Darwin: Die Abstammung des Menschen und die geschlechtliche Zuchtwabl, Stuttgart 1871 [engl. 1871]; das Zitat nach K. Groos: Die Anfänge der Kunst und die Theorie Darwins, in: Hessische Blätter für Volkskunde, 3/2-3 (1904), hier zit. nach dem Separatum, S. 16; positiv dagegen Sterne [wie Anm. 16], S. 88-101; vgl. auch den pro-evolutionären Diskussionsstand kurz vor 1900 bei C. Scott: Sex and Art, in: American Journal of Psychology, 7, 1895-96, S. 153-226; zur Rezeption von Darwin jetzt insgesamt W. Menninghaus: Das Versprechen der Schönheit, Frankfurt a. M. 2003, zu Darwins Auseinandersetzungen mit Zeitgenossen (insbesondere Ruskin) auch J. Smith: Charles Darwin and Victorian Visual Culture, Cambridge 2006, S. 27, 41 und $175 \mathrm{f}$.

80 Joly [wie Anm, 33], S. 362 f.: „Die Rasse, der jene Künstler aus Vézère, sowie ihre vielleicht noch unter uns lebenden Nachkommen angehören, wird von de Quatrefages und Hamy für einen Typus gehalten, den sie mit dem Namen Cro-Magnonrasse belegen; in den Guachen der Canarischen Inseln und namentlich in gewissen Kabylen von Bei-Menasser und Dschurdschura sehen sie die besterhaltenen Typen dieser mit so aussergewöhnlichem Zeichentalent begabten uralten Rasse. In Frankreich besitzt sie Nachkommen unter den jetzigen Basken von Zaraus, unter den Parisii des 5. Jahrhunderts und selbst unter gewissen Pariserinnen der Neuzeit." 
möglicherweise „noch sensibler" auf ästhetische Impulse reagiere als das weibliche (1896). ${ }^{81}$ Bei dem Gießener Philosophie-Professor Karl Groos findet sich dann in einem Darwin-kritischen Vortrag von 1904 Argumentation und Ironie vereint: "Was den ästhetischen Genuß betrifft, so könnte man es in unserem Zeitalter der Frauenbewegung von vorneherein für etwas bedenklich ansehen, daß diese Fähigkeit der Theorie nach primär nur dem auswählenden weiblichen Geschlecht zukommen würde -: die Genußfähigkeit des Mannes wäre ihm dann (wie etwa gewisse körperliche Charaktere) nur so nebenbei zugefallen. Ja mehr noch: wir hätten von Rechtswegen anzunehmen, daß der Anblick des Schönen in der Brust des Mannes überhaupt kein Lustgefühl, sondern eine dumpfe Regung eifersüchtiger Wut auf dessen Erzeuger entfachen müßte." ${ }^{82}$

Die wohl brillanteste Reaktion auf Darwins Ausführungen dürfte jedoch von dem in Böhmen geborenen, die meiste Zeit seines Lebens in Paris tätigen und später die abstrakte Malerei mitbegründenden Künstler František Kupka stammen: 1902 beschriftete er eine kleine, signierte und datierte Gouache mit dem Titel ANTROPOÏDES (Abb. 16). ${ }^{83}$ Dargestellt sind - so scheint es wenigstens auf den ersten Blick - zwei verbissen miteinander kämpfende Menschenaffen-Männchen, ein Gorilla und ein Orang-Utan, denen ein aufrecht stehendes Orang-Utan-Weibchen mit züchtig vor dem Bauch übereinander gelegten Armen interessiert, wenngleich abwartend zusieht. Offenbar ist sie Anlaß und ,Preis' des Kräftemessens, dessen tödlicher Ausgang sich für einen der Kontrahenten angesichts der steil abfallenden Uferklippen bereits abzeichnet. Allein schon die unnatürlich aufgerichtete Haltung des Weibchens macht allerdings klar, daß diese Anthro-

81 Scott [wie Anm. 79], S. 177 f.

82 Groos [wie Anm. 79], S. 5 f.

$8359,5 \times 62 \mathrm{~cm}$, Berlin, Sammlung Jiři Svestka; Venus et Caïn [wie Anm. 1], S. 36 f.; M. Theinhardt, P. Brullé: Kupka et la presse illustrée, «Des idées sérieuses sous une forme piquante", in: Vers des temps nouveaux. Kupka cuvres graphiques 18941912, Paris 2002, S. 58-73, hier S. 65, 68 und 215 (Kat. 57). - Wichtigstes formales Vorbild: Léon-Maxime Faivre: Envahisseur, 1884, Musée des Beaux-Arts et Archéologie, Vienne. - Spätere Bemerkungen des Künstlers zum Orang-Utan in F. Kupka: Die Schöpfung in der bildenden Kunst, Berlin 2001, S. 54. 
poiden als Sinnbilder für menschliches Verhalten zu verstehen sind - wenn überhaupt Menschenaffen dargestellt sein sollen und nicht evolutionäre Zwischenstufen von Affen und Mensch, die zwar ihre verwandtschaftliche Herkunft von Gorilla und Orang-Utan noch deutlich manifestieren würden, allerdings in einigen Verhaltensmustern bereits ,menschlich' geworden wären (vgl. Gabriel von Max' Gemälde des hypothetischen Pitecanthropus alalus, Leipzig, Haeckel-Haus). ${ }^{84} \mathrm{Zu}$ sehen ist also eine pointiert zugespitzte Situation „sexueller Zuchtwahl“, wobei der abgebildete Kampf der hochentwickelten Säugetiere eine von Darwin selbst formulierte Schwierigkeit seiner Theorie von der ästhetischer Selektion durch das Weibchen darstellt (die vor allem am Beispiel von Vögeln und Insekten belegt wurde) denn: „Bei den Säugetieren scheint das Männchen mehr gemäß dem Kampfgesetz als durch Entfaltung seiner Reize das Weibchen zu gewinnen." 85 Ironisiert wird diese Aussage bei Kupka vor allem auch durch den angedeuteten ,Blumenstrauß in der Hand der Umworbenen, wie ihn eine erste Fassung des Themas noch nicht aufwies ${ }^{86}$ und von dem bei Darwin natürlich nirgends die Rede ist: Erst diese zwei, drei roten Blumen - gängigstes Hilfsmittel menschlichen Liebeswerbens - entfalten die ganze Spannweite möglicher weiblicher Wahlkriterien von Ästhetik (und Kultur) bis hin zu rohem Kräftemessen. Man darf vermuten, daß dieser Blumenstrauß ein

84 Vgl. dazu A.E. Brehm, E. Pechuel-Loesche, W. Haacke: Brehms Tierleben. Allgemeine Kunde des Tierreichs - Die Sängetiere, Bd. 1, Leipzig/Wien 1900, wo S. 47 die Kämpfe von Affenmännchen (allerdings gleicher Spezies) um „die Oberherrschaft in der Leitung der Herde und in der Liebe" beschrieben werden, S. 41 zu ihren "Leidenschaften“, die „häufig einen vollständigen Sieg über ihre Klugheit“ davontragen und sie beherrschen, „just wie so manchen Menschen.“

85 Darwin [wie Anm. 79], S. 116; dieser Satz wiederum zitiert und kommentiert bei Groos [wie Anm. 79], S. 5: „Und unter den Säugetieren sind wieder die Affen keineswegs durch deutlich erkennbare Bewerbungskünste ausgezeichnet." Vgl. auch Scott [wie Anm. 79], S. 163-170 zu "combat" und "courting“ und dann S. $178 \mathrm{ff}$. zum entscheidenden Übergang von Affe zum prähistorischen bzw. ,primitiven' Menschen.

$86 \mathrm{Zu}$ dieser Kaltnadelradierung von ca. 1900-1902 s. Kupka œuvres [wie Anm 83], S. 215 (Kat. 56). 
Geschenk des männlichen Orang-Utans darstellte, der nicht nur von der gleichen Spezies wie das Weibchen und damit der naheliegendste Partner ist. Noch um 1900 galt häufig der Orang-Utan als der , menschlichste der Hominiden (im Gegensatz zum angeblich bösartigen Gorilla), wobei insbesondere die Weibchen dieser Menschenaffen eine angeborene Sittsamkeit an den Tag legten, die eben durch die Bildformel vor der Scham übereinandergelegter Hände und niedergeschlagenem Blick seit dem 17. Jahrhundert propagiert wurde (Abb. 17). Auf diese noch um 1900 weit verbreitete Legende über den asiatischen homo sylvestris dürfte noch Kupka mit seiner aufrecht stehenden Orang-Utan-Dame anspielen. ${ }^{87}$ Nun sieht sich auf dem Gemälde der Orang-Utan aber durch den Gorilla auf das Niveau des Zweikampfs zurückgeworfen. Und droht dabei nicht nur zu unterliegen mit dem Resultat, daß die Evolution nicht der Ästhetik, sondern dem Gesetz des Stärkeren folgen würde. Wobei das Weibchen der schieren Muskelkraft mindestens so viel Gefallen und Überzeugungskraft wie den Blumen abzugewinnen scheint. Wiederum nur spekulieren läßt sich schließlich über die mehr als ungewöhnliche Wahl des Ortes, die Klippe am Meer unter blauweißem Himmel und möglicherweise kurz nach Sonnenaufgang (wenn die Gelb- und Rot-Töne am Strand nicht nur als Sandfarbe, sondern auch als Reflex der noch tief stehenden Sonne zu lesen sind, worauf auch der noch im Schatten liegende felsige Vordergrund hinzuweisen scheint). Soll hier die Tageszeit metaphorisch (und ironisch) für die in zahlreichen Publikation zum vorgeschichtlichen Menschen beschworene, aufgehende Sonne menschlicher Vernunft stehen; soll die Naturschönheit der Landschaftskulisse mangelnde Empfindsamkeit und ästhetisches Unvermögen der Anthropoiden zusätzlich unterstreichen; soll mit Meer und Klippen gar auf die Geographie der britischen Insel und damit auf das Herkunftsland Darwins verwiesen werden?

87 Dazu L. Schiebinger: Am Busen der Natur. Erkenntnis und Geschlecht in den Anfängen der Wissenschaft, Stuttgart 1995, S. 114-167; eine ausführliche Widerlegung dieser Berichte unternehmen noch Brehm, Pechuel-Loesche, Haacke [wie Anm. 84], S. 92-103. Zur ,Rangfolge‘: „1. Schimpanse - 2. Gorilla-3. Orang-4. Neger“ vgl. auch Tf. XI in E. Haeckel: Anthropogenie, Leipzig 1874. 
Spätestens mit Blick auf die höhere Entwicklung der Bildkünste (ab der Jungsteinzeit) korrigierten sich dann freilich selbst die unkonventionellsten Denker, und in den Theorien und Darstellungen übernahmen erwartungsgemäß wieder männliche Künstler die Führungsrolle. Daß die avancierten Malereien Altamiras nicht von diesen, sondern von prähistorischen Künstlerinnen stammen könnten, wurde um 1900 offenbar nie erwogen. ${ }^{88}$

\section{„Psychische Einheit des Menschengeschlechts“ und, Weltkunstgeschichte aus primitiven Anfängen“}

Aus Anlaß des ersten Kongresses für Ästhetik und allgemeine Kunstwissenschaft war 1913 in Leizpig eine „Ausstellung zur vergleichenden Entwicklungsgeschichte der primitiven Kunst bei den Naturvölkern, den Kindern und in der Urgeschichte" zu sehen. Diese aus heutiger Sicht überraschende Verbindung und die begleitende Publikation dieser Schau können abschließend in aller Kürze andeuten helfen, welche weiteren Interessen zumindest die deutschsprachige Kunstgeschichte der Jahrzehnte um 1900 an den prähistorischen Bildwerken hatte: ${ }^{89}$ Es ging weniger um eine schlicht chronologische Ausweitung der Fachgrenzen in die Vorgeschichte als um zwei andere, wesentlich fundamentalere Fragen. Zum einen um die Untersuchung der ,Anfänge als A priori einer von den Grundlagen an wissenschaftlichen Kunstforschung und andererseits um die Analyse materieller Hinterlassenschaften als (einzigem) Zugang zu schriftlosen Kulturen. Allerdings waren diese Fragen eben nicht mehr allein am sehr unvollständigen vorgeschichtlichen Material zu klären, vielmehr mußten dafür auch die noch existierenden ,primitiven' Kulturen außerhalb Europas und die ersten Kunstübungen von Kindern einbezogen werden. ${ }^{90}$

88 Vgl. dann Raphael [wie Anm. 35], S. 32.

89 K.H. Busse: Die Ausstellung zur vergleichenden Entwicklungsgeschichte der primitiven Kunst bei den Naturvölkern, den Kindern und in der Urzeit, in: Kongress für Asthetik und Allgemeine Kunstwissenschaft [...] Bericht, Stuttgart 1914, S. 79-82.

90 Im frühen 20. Jh. resümiert diese Probleme vielleicht am besten A. Vierkandt: Prinzipienfragen der ethnologischen Kunstforschung, in: Zweiter Kongreß für Ästhetik 
Das verheißungsvollste Versprechen, wie eine, strenge Kunstwissenschaft zu begründen sei, gab ab der Mitte des 19. Jahrhunderts die (Wahrnehmungs-)Psychologie im Gefolge Johann Friedrich Herbarts. In Parallele zur medizinisch-biologischen Anthropologie, die das Lebewesen Mensch in seinen Gesetzmäßigkeiten bestimmte, sollte eine solche Psychologie die Gesetze der Geistesvorgänge des Menschen ermitteln (und damit zugleich die Verbindung zwischen Physis und Psyche/Geist schaffen): Für die Kunstgeschichte und insbesondere die Vertreter der Einfühlungsästhetik war damit die Vorstellung verbunden, daß bestimmte visuelle Formen bestimmte, immer gleiche, anthropologisch konstante Grundreaktionen hervorriefen und damit erst die Möglichzeit zur rückblickenden kunsthistorischen Analyse über Jahrhunderte hinweg schufen. Allerdings wurde schnell deutlich, daß dieser psychologische Erklärungsansatz - wollte er über diese Grundreaktionen hinausgehen - nicht nur isoliert das Individuum in den Blick nehmen durfte, sondern als eine Art von ,Völkerpsychologie' betrieben werden mußte: Denn erst der Blick auf ganze Volksgruppen ließ die in allen Individuen einer Kultur, Region oder ,Rasse w wirkenden Faktoren und Gemeinsamkeiten erkennen, erst dieser synthetisierende Blick erlaubte, größere chronologische und lokale Zusammenhänge zu untersuchen, erst so wurde es möglich, Vergleiche zwischen kulturellen Gruppen anzustellen. ${ }^{91}$ Alle theoretischen Ansätze dieser Richtung basierten dabei in hohem Maße auf der Interpretation, primitiver' Menschen, ihrer Leistungen und Produkte, denn nur diese einfachen ,Anfangsstufen ${ }^{6}$ schienen den For-

und Kunstwissenschaft [...] Bericht, Stuttgart 1925, S. 338-355; ausführlich dazu auch Pfisterer [wie Anm. 30].

91 Aus der umfangreichen, allerdings nie umfassenden Literatur dazu sei nur hingewiesen auf Ch. G. Allesch: Geschichte der psychologischen Ästhetik. Untersuchungen zur historischen Entwicklung eines psychologischen Verständnisses ästhetischer Phänomene, Göttingen u. a. 1987; H. F. Mallgrave, E. Ikonomou: Introduction, in: dies. (Hg.), Empathy, Form, and Space. Problems in German Aesthetics, 1873-1893, Los Angeles 1994, S. 1-85; M. Bunzl: Völkerpsychologie and German-Jewish Emancipation, in: ders., H.G. Penny (Hg.): Wordly Provincialism. German Antbropology in the Age of Empire, Ann Arbor 2003, S. 47-85; J. Müller-Tamm: Abstraktion als Einfüblung, Freiburg i. Br. 2005. 
schern überhaupt Zugangsmöglichkeiten zu eröffnen - bei den weiter entwickelten Kulturen sah man sich derart komplizierten Prozessen der Ausdifferenzierung, Überlagerung, Beeinflussung, Reflexion usw. gegenüber, daß an ihnen keine klare Sicht auf die Grundprinzipien mehr zu gewinnen war. Was aus diesen Erkenntnissen für die Kunstproduktion der Menschheit zu gewinnen war, legten dann vor allem 1894 Ernst Grosse und 1900 Yrjö Hirn in ihren großen Entwürfen einer Kunstwissenschaft dar, die konsequent von den Prinzipien der ,Anfänge der Kunst' ausgehend eine umfassende Herangehensweise an alle Kunst zu ermitteln versuchten. ${ }^{92}$

Darüber, wie die verschiedenen Kulturstufen der Menschheit zueinander in Relation zu setzen seien, wurde jedoch kontrovers diskutiert. Das letztlich international erfolgreichste Modell war der vor allem im anglo-amerikanischen Raum favorisierte, unilineare Evolutionismus', dessen Credo etwa bereits 1844 Robert Chambers auf der ,Rassen-Ebene‘ zusammenfaßte: "The leading characters, in short, of the various races of mankind are simply representations of particular stages in the development of the highest Caucasian type." 93 Daraus folgerte aber auch, daß die Entwicklung aller Kulturen weltweit quasi naturgesetzlich auf ihre Vollendung in der europäischen Zivilisation zulief; oder anders gesagt: nach ihren ,Entwicklungsstufen' geordnet, schienen die unterschiedlich weit fortgeschrittenen Gruppen der Menschheit den Gang der Geschichte beinahe vom ,Anfang` bis zur aktuellen Höhe zu spiegeln. Vor allem der deutschsprachige Bereich jedoch setzte ab den 1860er Jahren dieser Theorie die kombinierte Vorstellung von der „psychischen Einheit des Menschengeschlechts“, die letztlich eine Gleichwertigkeit aller Menschen aller ,Kulturstufen' postulierte, und zugleich der unabhängigen, eigenständigen Weiterentwicklung der ver-

92 E. Grosse: Die Anfünge der Kunst, Freiburg i. Br. 1894; Y. Hirn: The Origins of Art. A psychological \& sociological inquiry, London 1900 [dt. Übersetzung 1902].

93 R. Chambers: Vestiges of the natural history of creation, London 1844, S. 307. - Zu den größeren Zusammenhängen H.-J. Koloß: Der ethnologische Evolutionismus im 19. Jahrhundert, in: Zeitschrift für Ethnologie, 111, 1986, S. 15-45; P.J. Bowler: From 'savage' to 'primitive': Victorian evolutionism and the interpretation of marginalized peoples, in: Antiquity, 66, 1992, S. 721-729. 
schiedenen Kulturen entgegen: Als wichtigste Autorität vertrat Adolf Bastian diese Position, die der Sache nach aber bereits in Herders und Wilhelm von Humboldts Theorien zur Kulturgeschichte angelegt und dann etwa schon bei einflußreichen Forschern wie Theodor Waitz oder Moritz Steinthal und Hermann Lazarus in ihrer theoretischen Tragweite ausformuliert war: ${ }^{94}$ Nach dieser Vorstellung ließen sich die verschiedenen kulturellen Erscheinungsformen der Welt nicht mehr auf einen Entwicklungsgang reduzieren, sondern stellten - kurz gesagt - alternative, nicht ineinander überführbare, gleichwertige Ausprägungen durch unterschiedliche Einfluß-Faktoren dar. Mit diesem kulturellen Relativismus fiel zumindest theoretisch erstmals die Vorrangstellung Europas. Für die Kunstgeschichte resultierte daraus mit einiger Verzögerung eine radikale Abkehr vom etablierten ästhetischen Kanon. Denn wenn ,Kunst eine anthropologische Konstante des Menschseins darstellte, die ihn von seinen Anfängen an begleitete, wie die neuen prähistorischen Funde bewiesen, dann galt es nun, den künstlerischen Wert aller dieser, primitiven' Kunstformen zu akzeptieren und zu verstehen. Damit ist die Intention der bereits zitierten Bücher von Grosse und Hirn ebenso umrissen wie das Programm der Ausstellung 1913 in Leipzig. Das Jahr 1923 markiert dann den Höhepunkt dieser Entwicklung, u. a. mit Herbert Kühns Buch Die Kunst der Primitiven, in dem sich nun gemäß dieser Logik leicht nachvollziehbar die prähistorische Kunst als der ,absolute Anfang' (in Farbabbildung vertreten durch die Wandmalereien Altamiras) reiht neben die Kunstprodukte der Buschmänner, Azteken, Eskimos, Australier usw. und damit neben verschiedene Formen ,entwicklungsgeschichtlicher Anfänge, die aber zugleich vollgültige

94 Etwa K.-P. Koepping: Adolf Bastian and the psychic unity of mankind. The foundations of anthropology in nineteenth-century Germany, Münster/Hamburg 2005 (1983); I. Kalmar: The Völkerpsychologie of Lazarus and Steinthal and the Modern Concept of Culture, in: Journal of the History of Ideas, 48, 1987, S. 671-690; M. Bunzl: Franz Boas and the Humboldtian Tradition. From Volksgeist and Nationalcharakter to an Anthropolocial Concept of Culture, in: G.W. Stocking, Jr. (Hg.): Volksgeist as Method and Ethic. Essays on Boasian Ethnography and the German Anthropological Tradition, Madison 1996, S. 17-78. 
Ausdrucksformen des menschlichen Kunstschaffens darstellen: „Unsere Zeit - arm und reich zugleich - tritt heraus aus dem engen Rahmen europäischer Kunstbetrachtung, ungemessen erweitert sich das Bild, die ersten Schritte werden getan zur Weltgeschichte der Kunst. [...] Die Kunst der Primitiven ist in Wirklichkeit nicht primitiv - der Mensch der Zeit lebt primitiv, seine Wirtschaftsform ist primitiv - seine Kunst ist reinster Ausdruck seiner Welt, die nie primitiv, sondern nur anders geschaut, unter anderen Formen erlebt ist. [...] So müssen wir sie sehen unter völlig anderem Aspekt. Die Begriffe Winckelmanns und Goethes reichen nicht mehr zu, die Kunst der Urvölker, der Naturvölker zu deuten. Eine Zeit, die das Griechentum und Renaissance allein als die Höhe der Kunst erscheint und jede stilisierte Richtung als ein Verfall, wird kein Verständnis haben für die Kunst der primitiven Völker." 95

Angesichts dieses Paradigmenwechsels scheint die zweite Hauptmotivation der Kunstgeschichte für eine Beschäftigung mit ,anfänglicher Kunst fast in ihrer Bedeutung zurückzutreten - und doch ist auch diese grundlegend: Die Beschäftigung mit den ,primitiven' Bildwerken hätte das Fach dazu führen müssen, sich endgültig von den Geschichts- und Sprachwissenschaften zu emanzipieren. Denn die neue Tendenz, Weltgeschichte und umfassende Kulturgeschichte zu schreiben, führte in diesen Disziplinen notwendig zu einem neuen Interesse auch an den Zeiten und Völkern, die keine schriftlichen Aufzeichnungen angefertigt hatten oder anfertigten. Dabei aber waren die Historiker und Sprachforscher erstmals unausweichlich auf die Ergebnisse kunstgeschichtlicher Analyse der hinterlassenen Bildwerke (und allgemeiner: der materiellen Kultur) und der exklusiv aus diesen Relikten rekonstruierbaren Geistes-Prozessen angewiesen. Oder wie es Karl Lamprecht 1905 zugestanden hatte, dessen Leipziger Institut für verglei-

95 H. Kühn: Die Kunst der Primitiven, München 1923, S. 7; ähnlich ders.: Die Bedeutung der prähistorischen und ethnographischen Kunst für die Kunstgeschichte, in: IPEK. Jabrbuch für prähistorische und ethnographische Kunst, 1, 1925, S. 3-13. Vgl. jedoch auch schon G. Grant MacCurdy: The Dawn of Art: Cave Paintings, Engravings and Sculpture, in: Art and Archaeology, 4, 1916, S. 71-90. 
chende Kulturforschung nicht zufällig dann 1913 Gastgeber des Kongresses für Ästhetik und allgemeine Kunstwissenschaft und der begleitenden Ausstellung sein sollte: „[...] Reduziert sich damit die Frage nach der Aufstellung der Zeitalter niedriger Kultur -, oder was dasselbe ist, das Problem der Analyse des ungeheueren völkerkundlichen Stoffes nach historischen Kategorien - zunächst auf die Phantasietätigkeit, so kann und muss sie auf diesem Gebiet [...] auf eine Untersuchung der bildenden Kunst beschränkt werden." 96

Die Kunstgeschichte sollte es freilich nicht schaffen, die zu beiden Fragen erzielten Ansätze und Ergebnisse über die Zäsur von 1933-1945 hinweg $\mathrm{zu}$ retten, ${ }^{97}$ geschweige denn, diese schon vorher fest in den mainstream ihrer Forschung einzuspeisen und dort zu verankern. Im Gegenteil: Die ,primitiven' Kunstobjekte wurden zunehmend den neuen Fächern der Ur- und Frühgeschichte und der Völkerkunde/Ethnologie überlassen und der Blickwinkel wieder auf die Grenzen des nachantiken Europas (und Nordamerikas) reduziert. Indem so die Kunstgeschichte die Probleme, die ihr Altamira und die prähistorische und ,primitive‘ Kunst insgesamt spätestens ab 1879/80 stellten, umging, hat sie wohl ihre größte Chance verspielt, um 1900 zu einer geisteswissenschaftlichen Leitdisziplin aufzusteigen.

96 K. Lamprecht: Universalgeschichtliche Probleme vom sozialpsychologischen Standpunkte, in: ders.: Moderne Geschichtswissenschaft. Fünf Vorträge, Freiburg i.Br. 1905, S. 103-130, hier S. 118 f. und 123 f.; zum großen Kontext St. Haas: Historische Kulturforschung in Deutscbland 1880-1930. Geschichtswissenschaft zwischen Synthese und Pluralität, Köln u. a., und Cartier [wie Anm. 32].

97 M. Halbertsma: Fremde Welten und vertraute Methoden: die deutsche Weltkunstforschung des frühen 20. Jahrhunderts, in: Kritische Berichte, 31, 2003, S. 28-36; Pfisterer [wie Anm. 30]. 


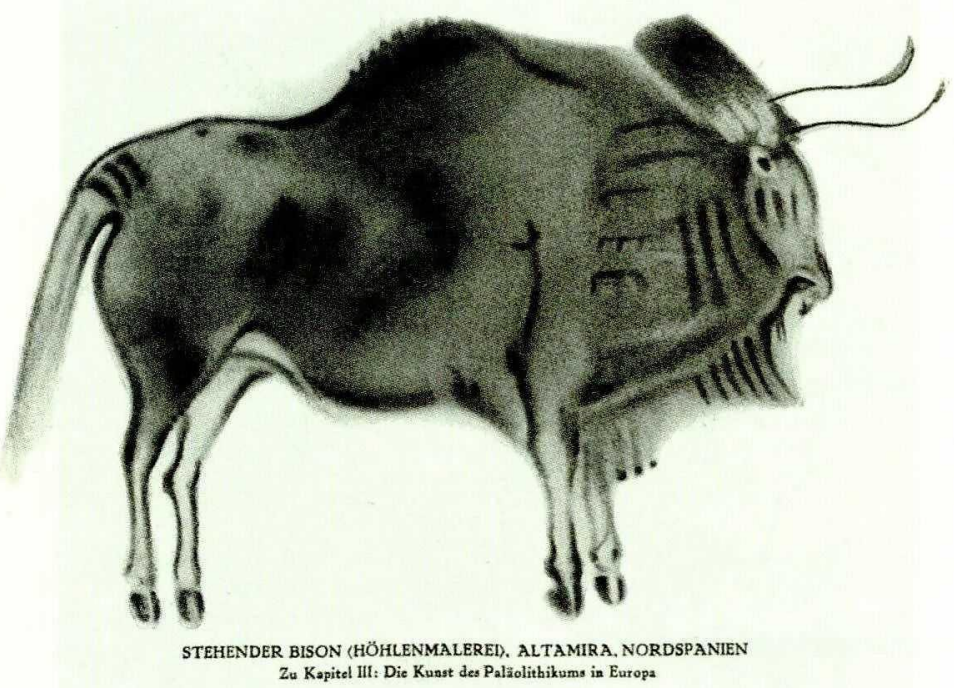

Abb. 1 Stier aus Altamira, aus: H. Kühn: Die Kunst der Primitiven, München 1923, Taf. nach S. 28.

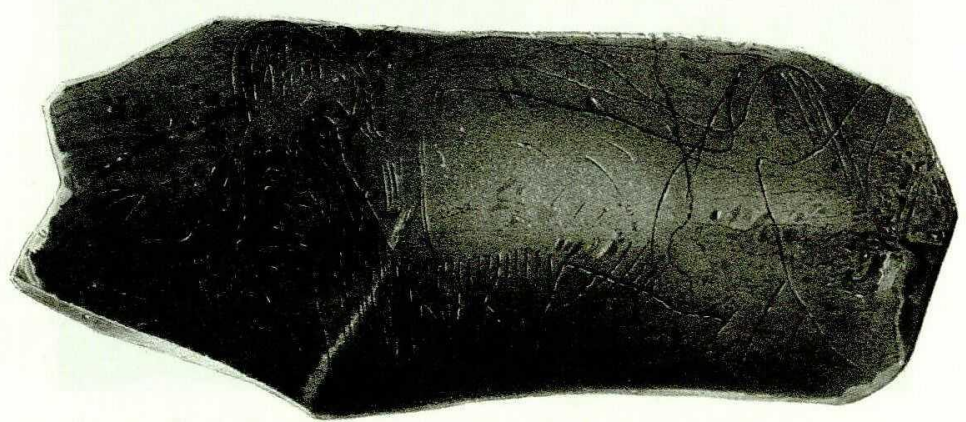

Abb. 2 Mammut, aus: É. Lartet, H. Christy: Reliquiae Aquitanicae, London 1865-1875, Teil B, Taf. 28. 


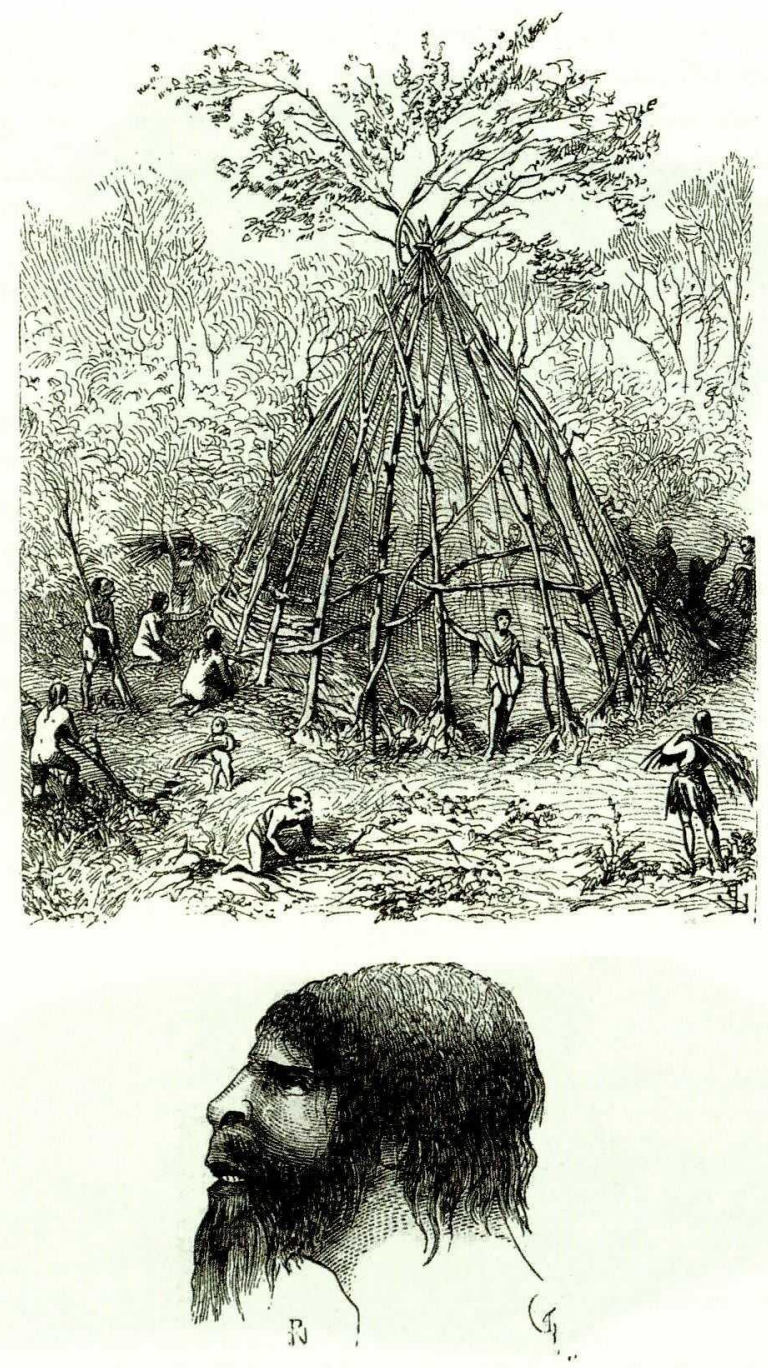

Abb. 3 Urhütte und Urmensch, aus: E.-É. Viollet-le-Duc: Histoire de l'habitation humaine, Paris 1870, S. 4-7. 


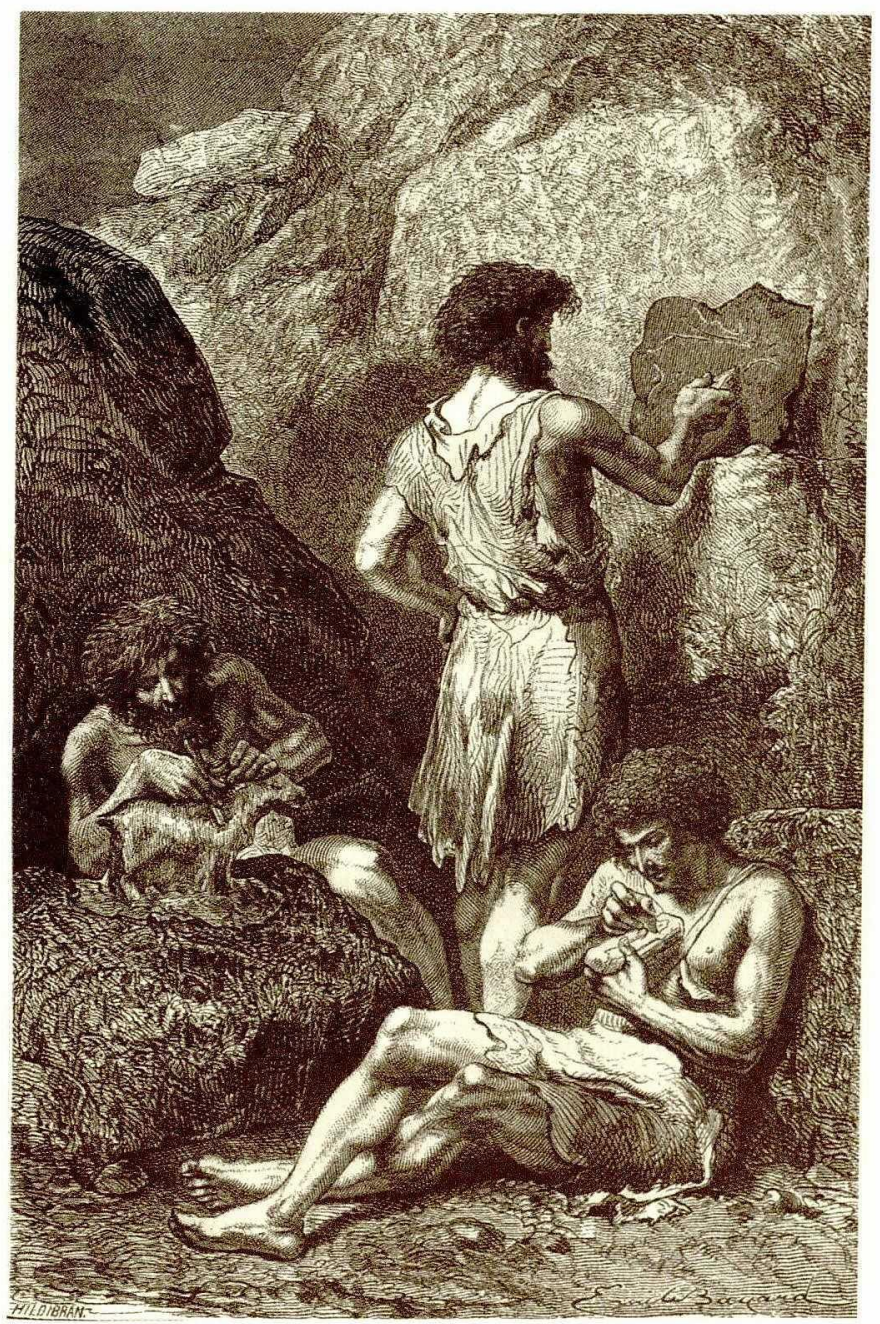

Abb. 4 Émile Bayard, Les précurseurs de Raphaël et Michel-Ange, ou la naissance des arts du dessin et de la sculpture à l'époque du renne, aus: L. Figuier: L'bormme primitif, Paris 1870, fig. 67. 


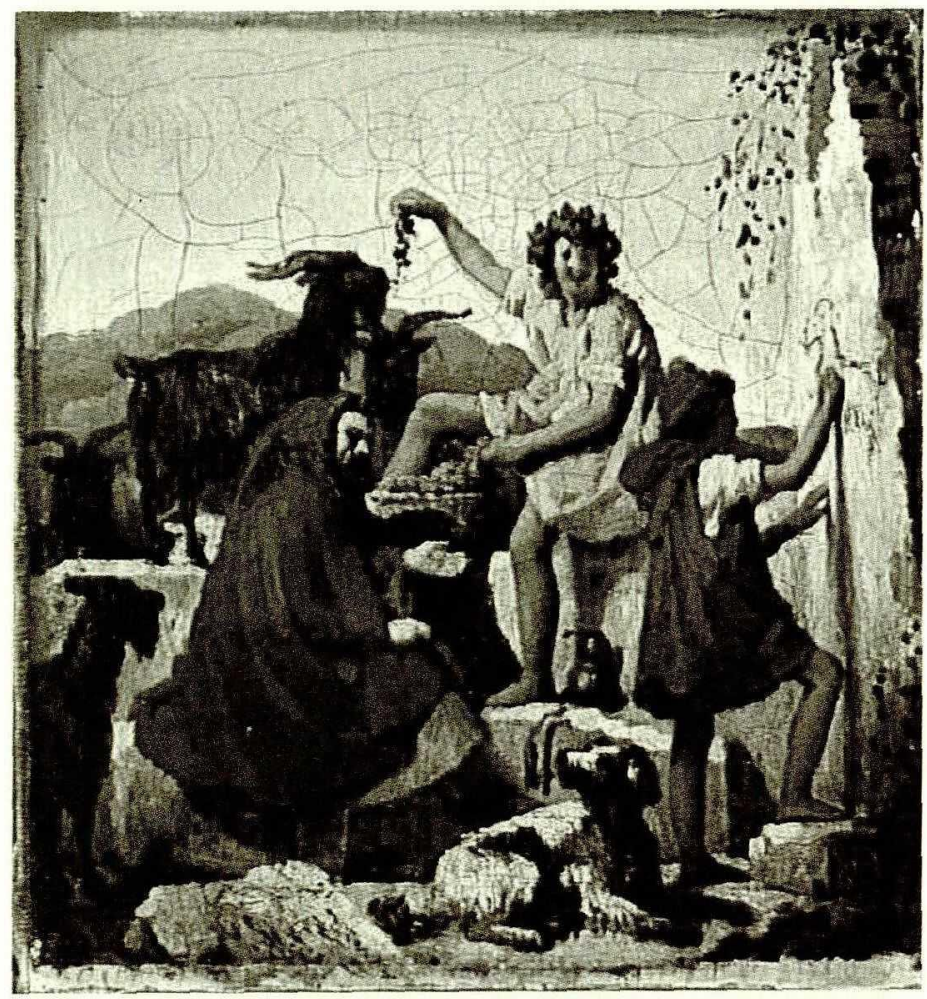

Abb. 5 Henri-Joseph de Forestier, Die Kindheit Giottos, 1. Hälfte 19. Jahrhundert, Dijon, Musée Magnin. 


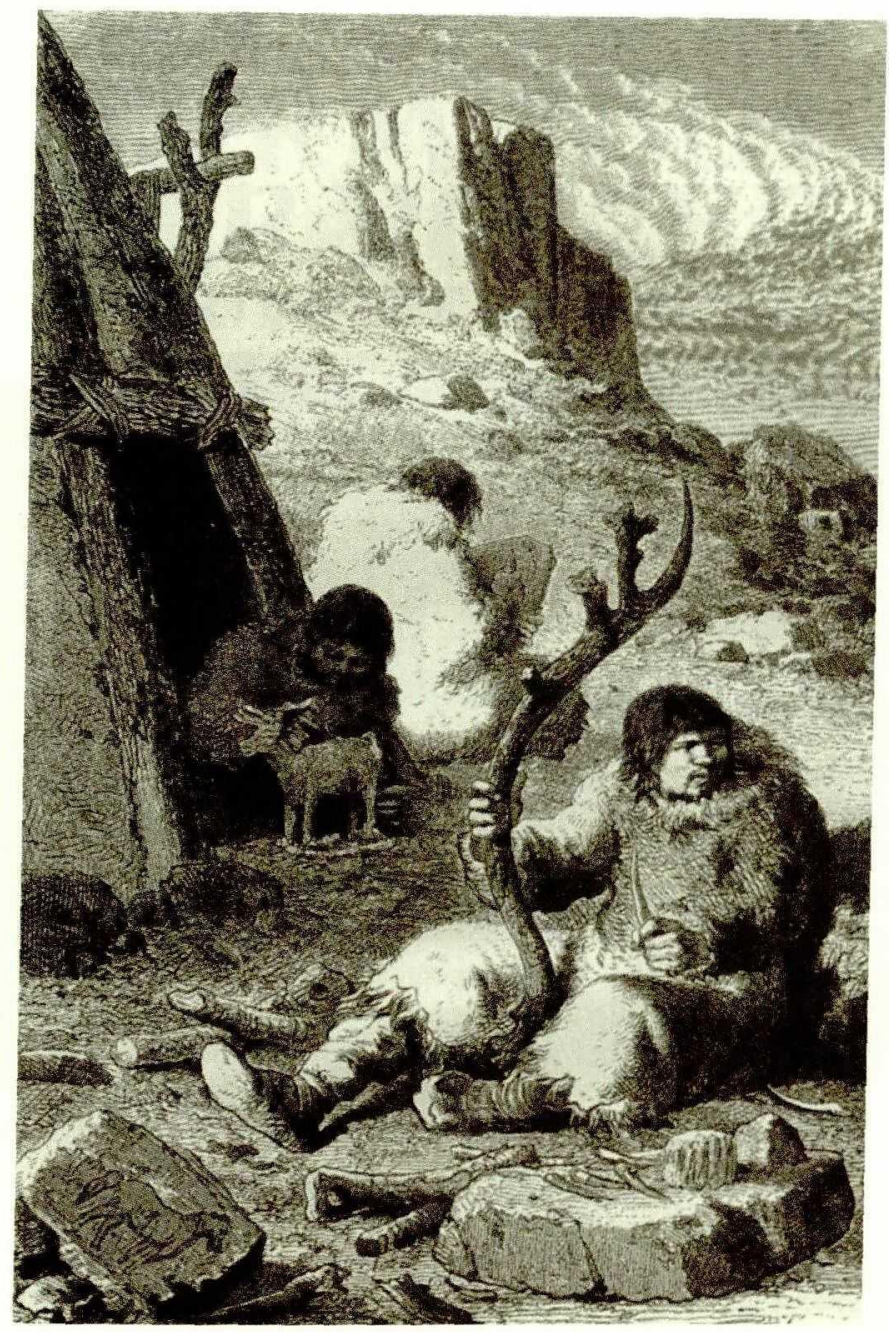

Abb. 6 Émile Bayard, Les précurseurs de Raphaël et Michel-Ange, ou la naissance des arts du dessin et de la sculpture à l'époque du renne, aus: L. Figuier: L'bomme primitif, Paris ${ }^{2} 1870$, fig. 67. 


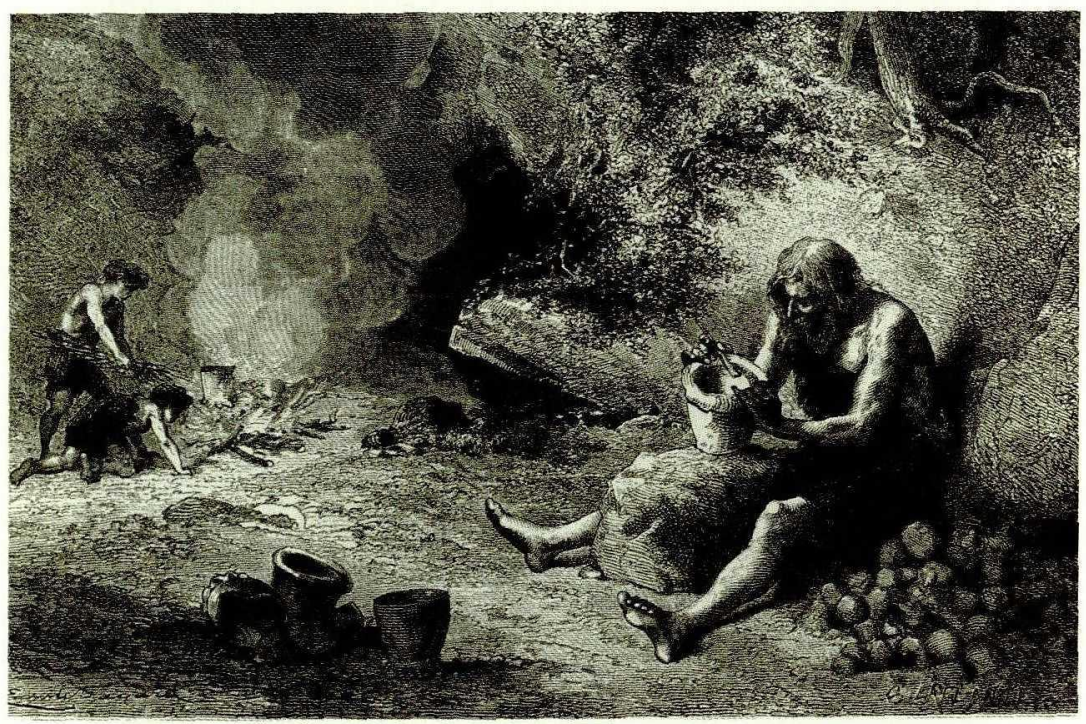

Abb. 7 Émile Bayard, Le premier potier, aus: L. Figuier: L'bomme primitif, Paris 1870 , fig. 17. 

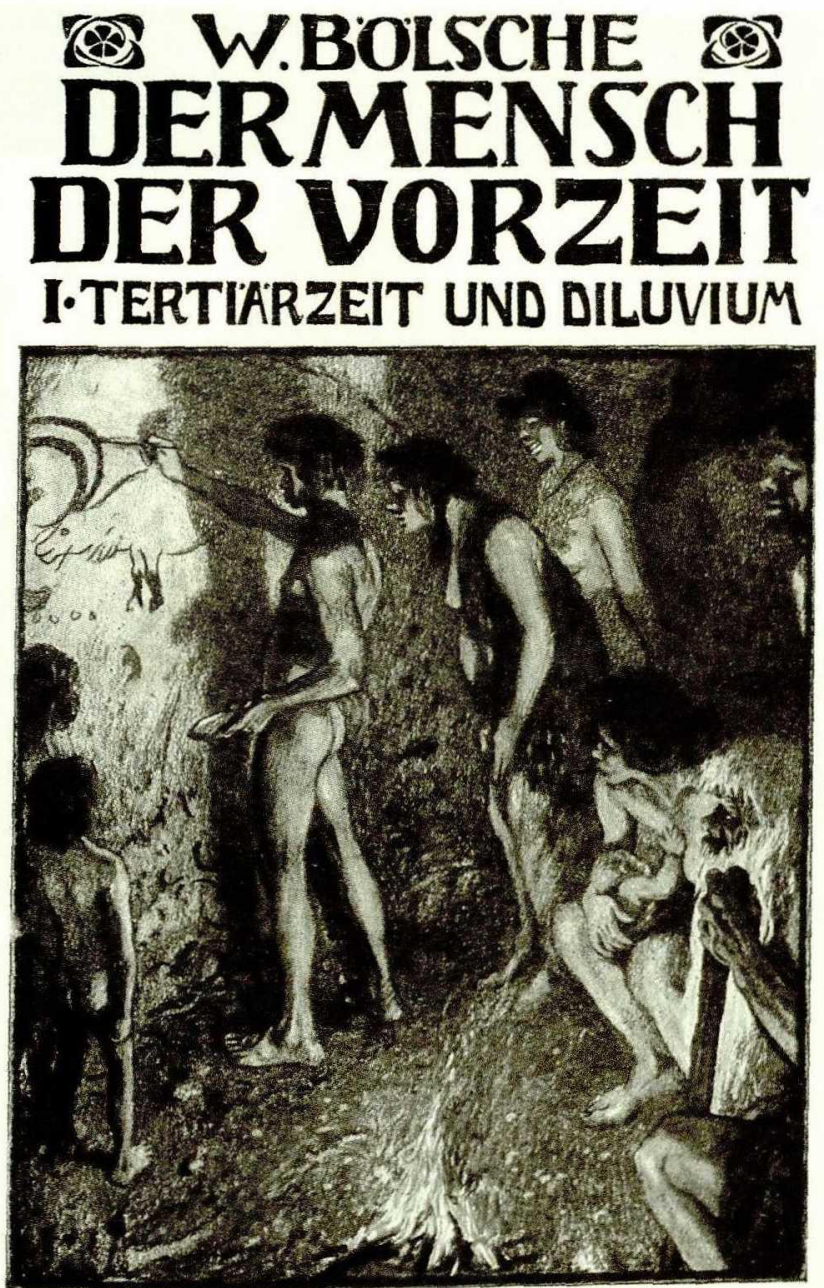

Kosmos Gesellschaft der Naturfreunde

Abb. 8 Wilhelm Bölsche, Der Mensch der Urzeit. I. Tertiärzeit E Diluvium, Stuttgart 1909, Frontispiz. 


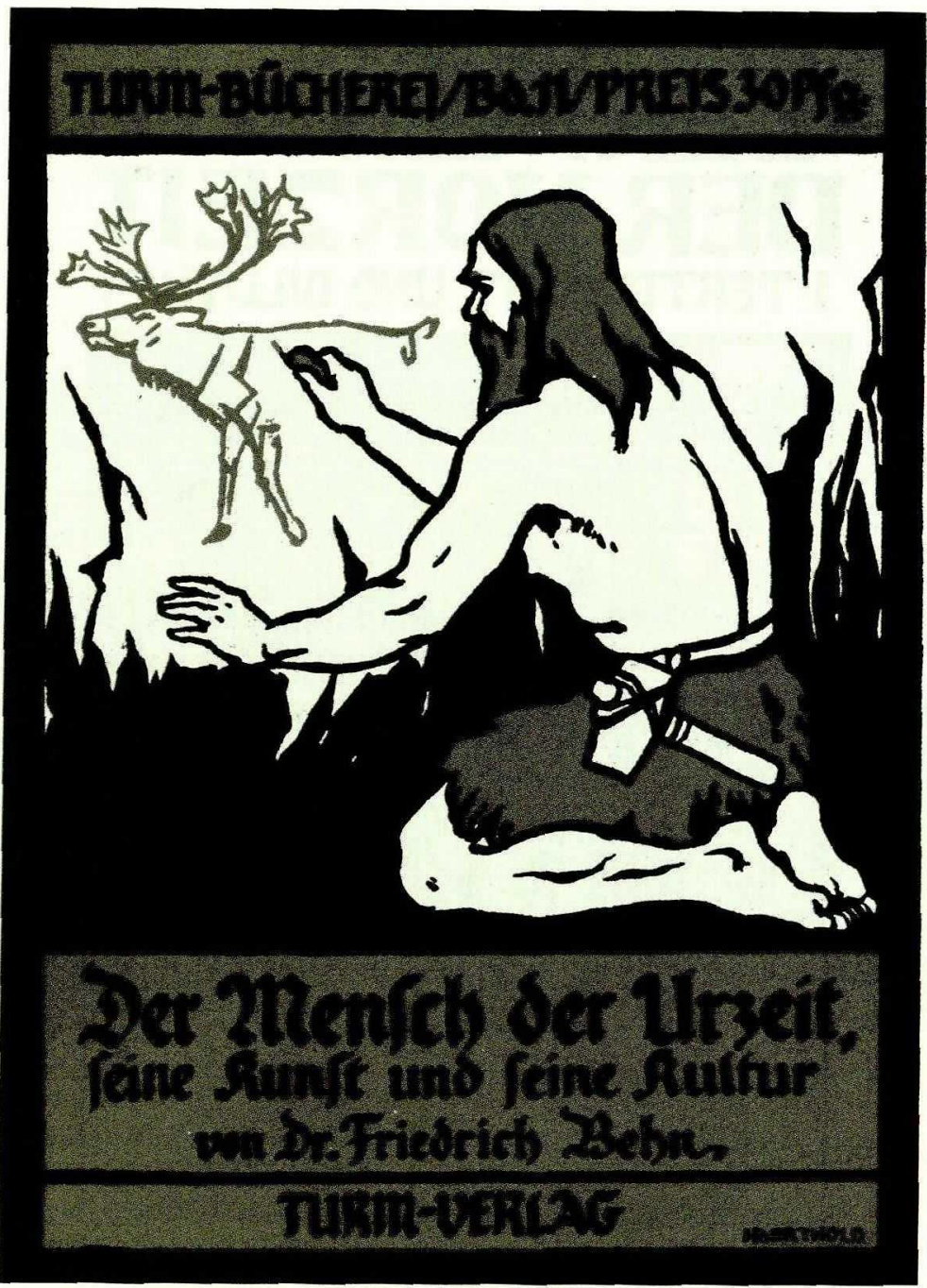

Abb. 9 Friedrich Behn, Der Mensch der Urzeit, seine Kunst und seine Kultur, Leipzig 1913, Umschlag. 


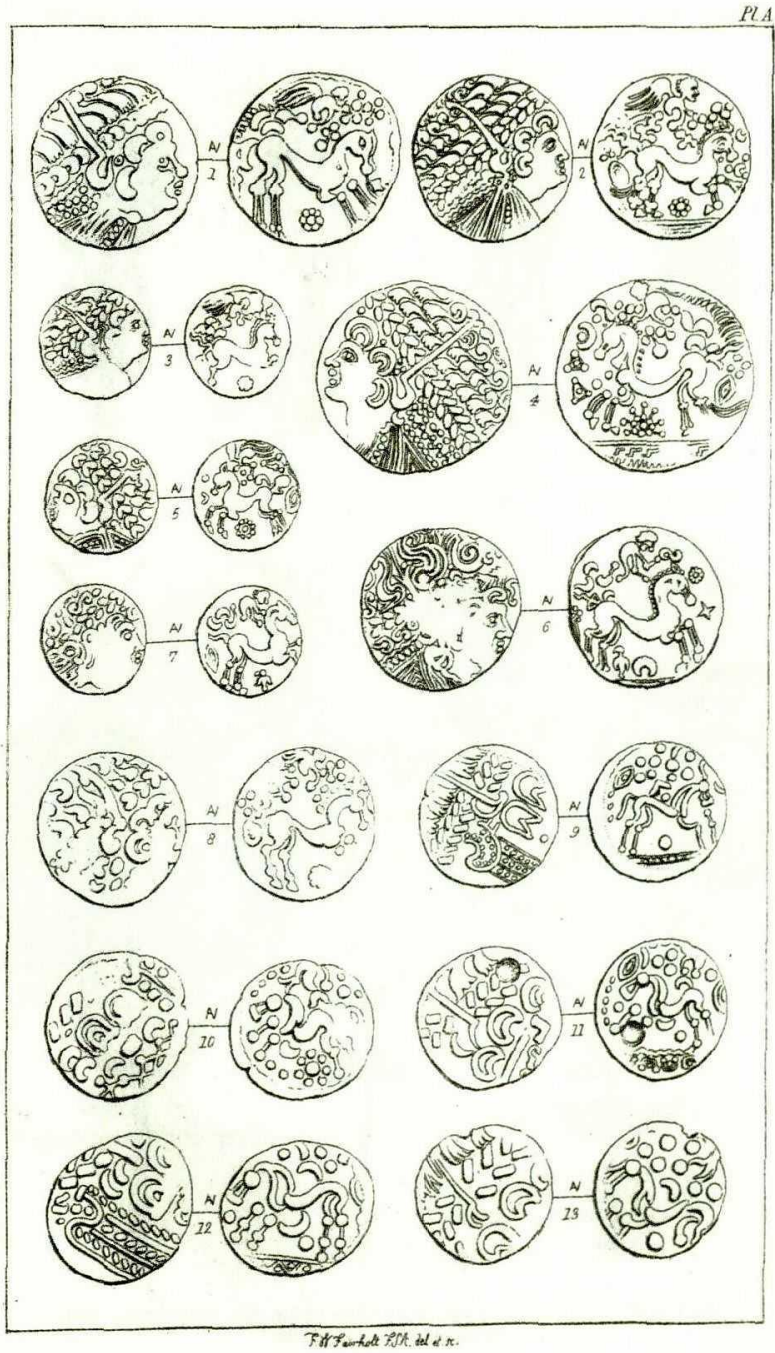

Abb. 10 John Evans, The Coins of the Ancient Britons, London 1864, Taf. A. 
[P.R.I.G.B., VII. Pl.iv = J. A. I., IV. Pl.xxii.] Plate IV.

Fig. 1.

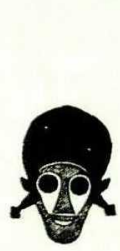

Fig. 2

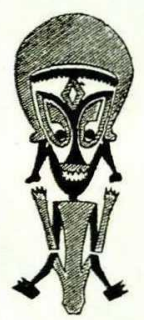

Fig. 6.
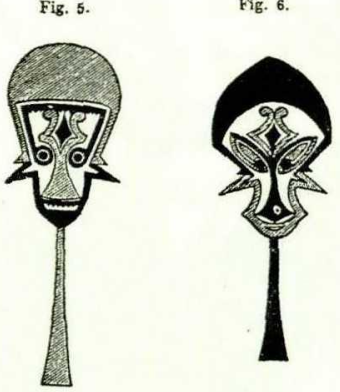

Fig. 10.
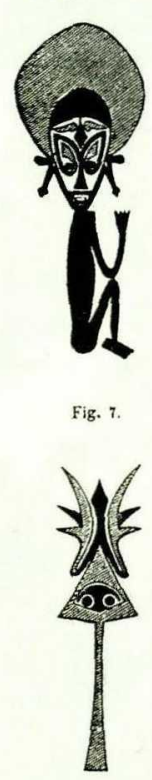

Fig. 7.

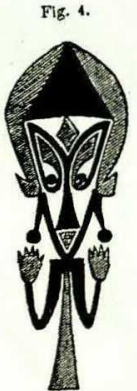

Fig. 8.
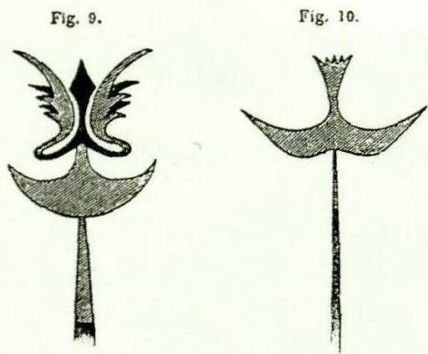

Fig. 11.

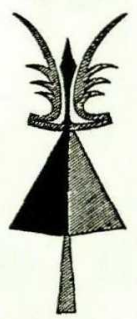

ORNAMPNTATYON OF NEW IRELAND PADDLES, SHOWING THE TRANSITION OF FORM.

Abb. 11 Augustus Henry Lane Fox Pitt Rivers, The Evolution of Culture and Other Essays, Oxford 1906, Taf. V. 


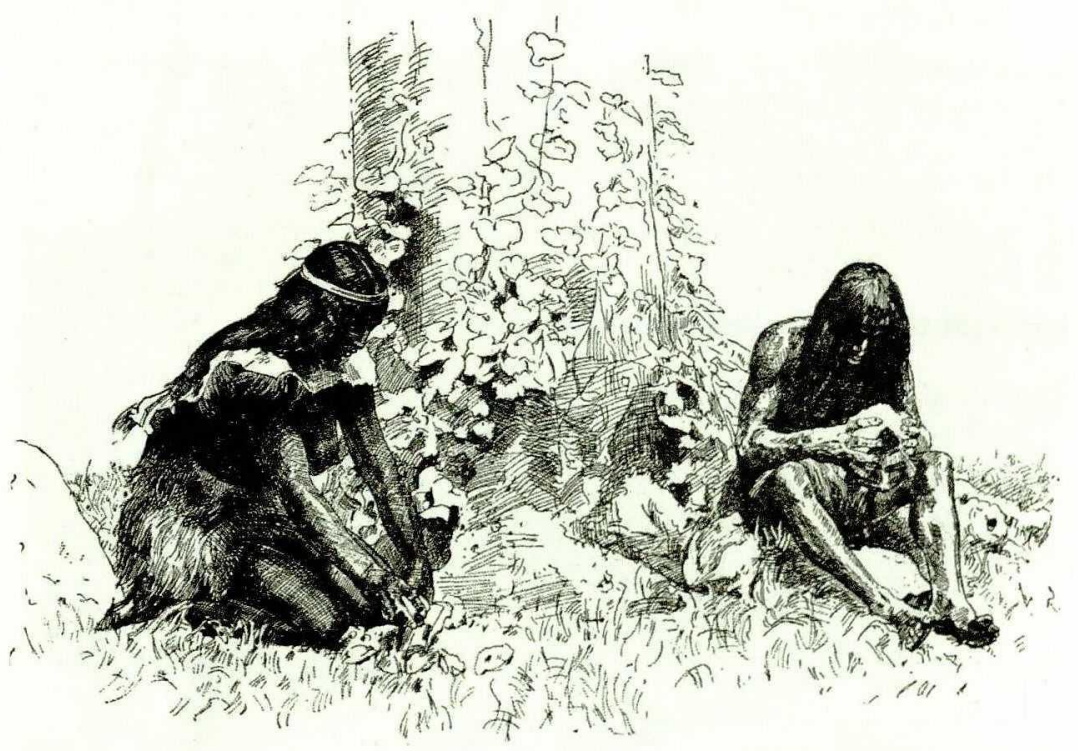

Abb. 12 L'Exposition Universelle de 1889, Paris 1889, Bd. 1, S. 295. 


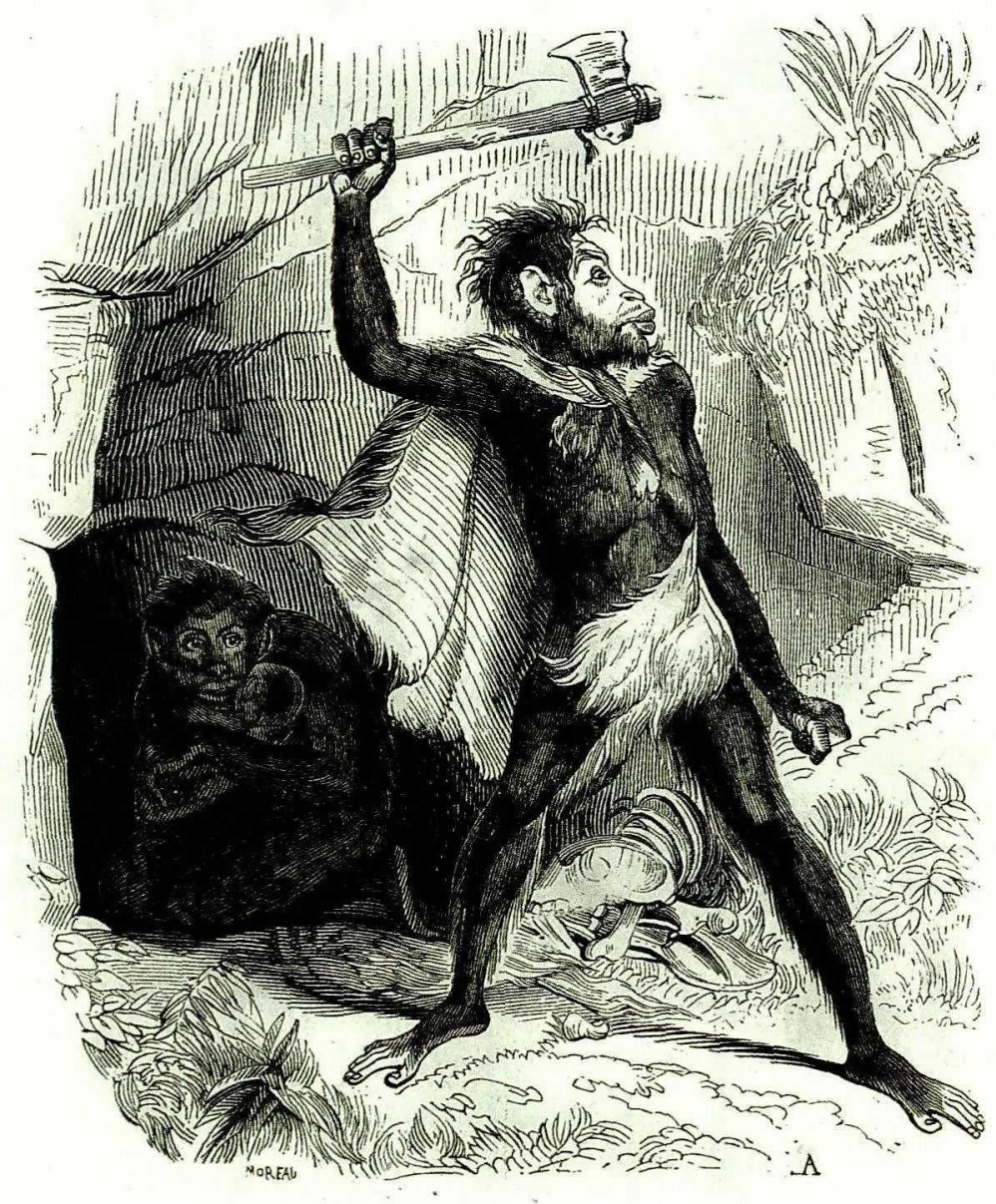

L'HOMME FOSSILE.

Abb. 13 Pierre Boitard: Paris avant les hommes ..., Paris 1861, Frontispiz. 


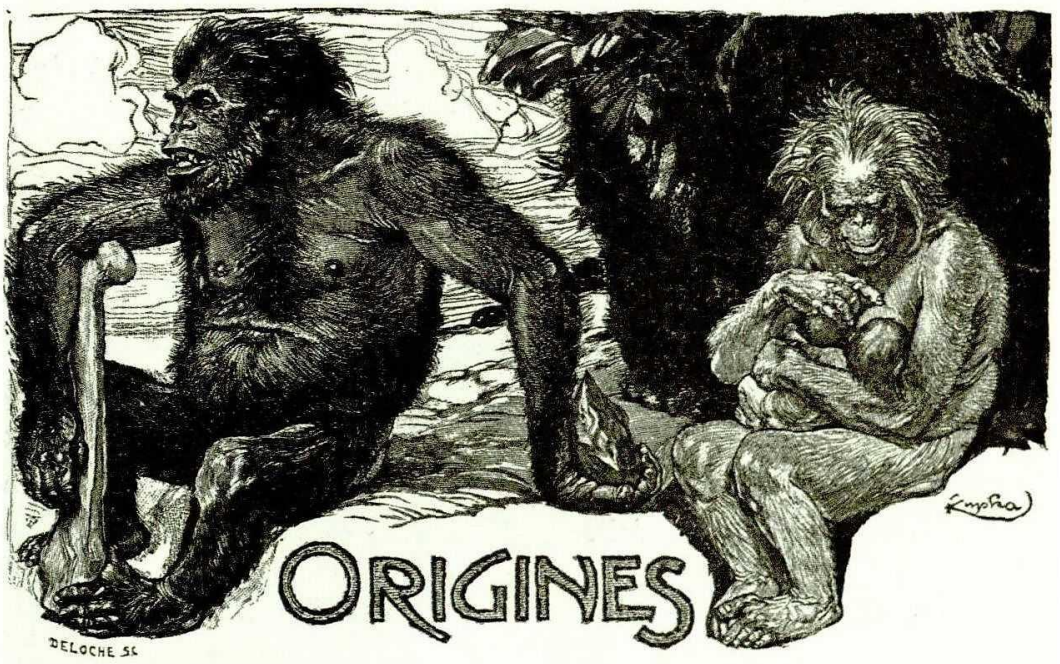

Abb. 14 František Kupka, Origines, Vignette am Kapitelanfang, aus: E. Réclus: L'Homme et la Terre, Paris 1905, Bd. 1, S. 3. 


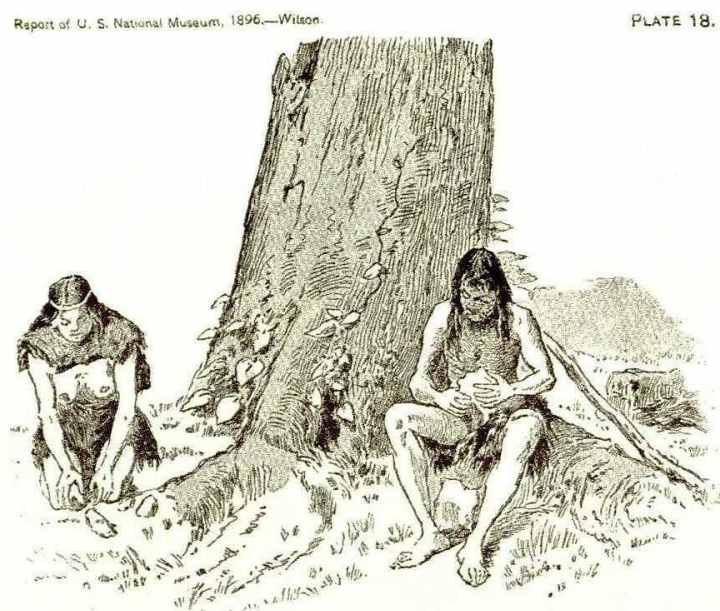

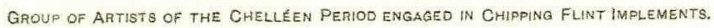

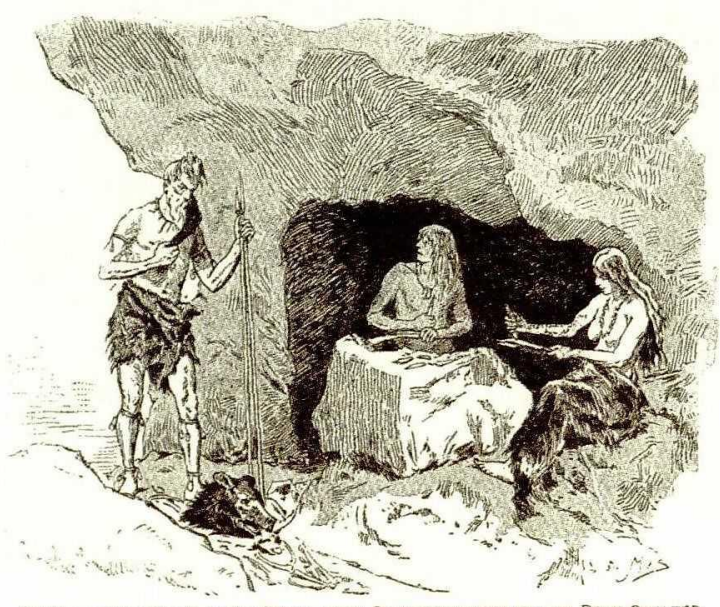

FAMILY OF THE MADELAINIEN EPOCH, WITH REPRESENTATION OF THE ROCK SHELTER of LAUGERIE BASSE.

From groups at Paris Expesition, 1899.

Abb, 15 Thomas Wilson, Prehistoric Art; or the origins of art as manifested in the works of prehistoric man, Washington 1898, Taf. 18. 


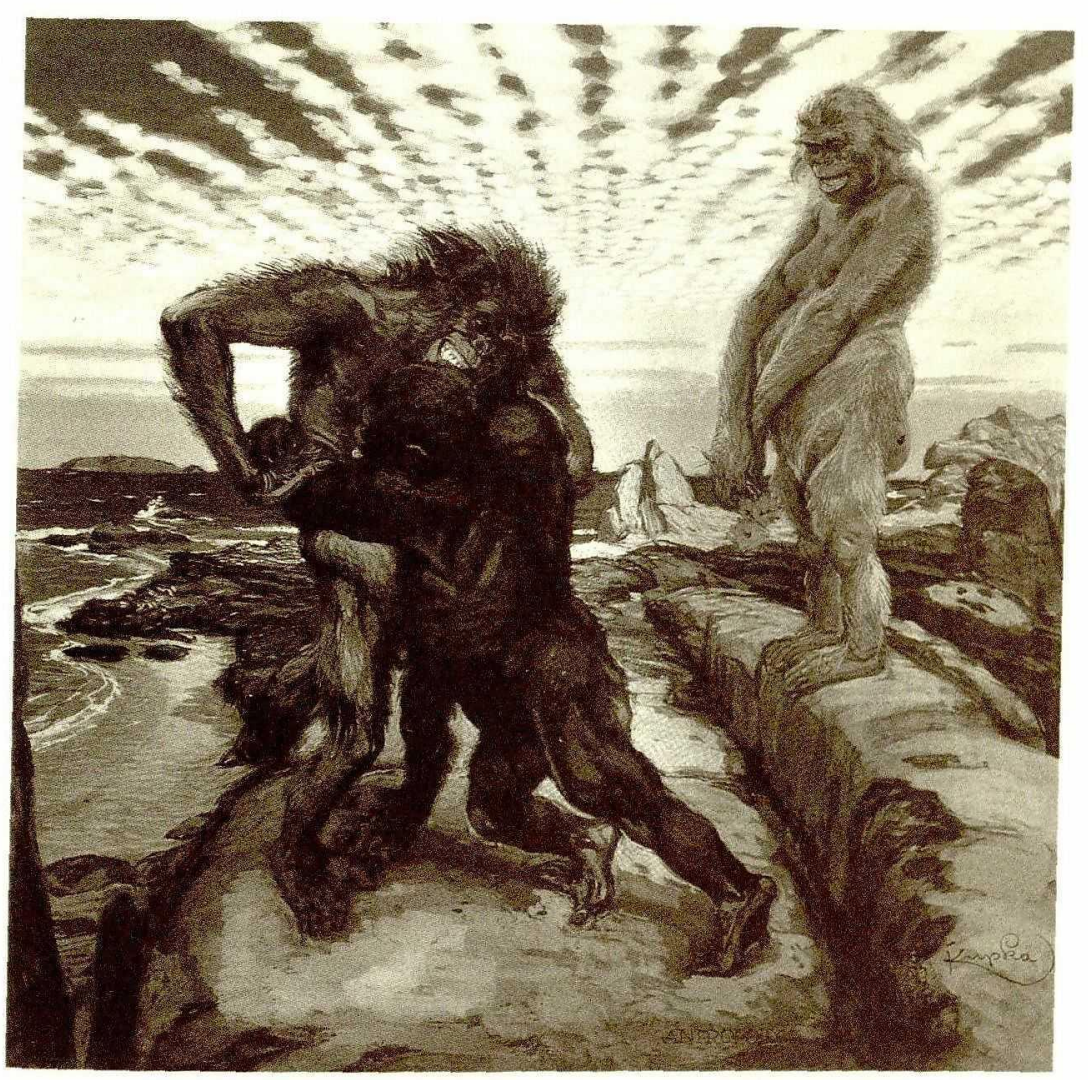

Abb. 16 František Kupka: ANTROPOÏDES, 1902, Berlin, Sammlung J. Svestka. 


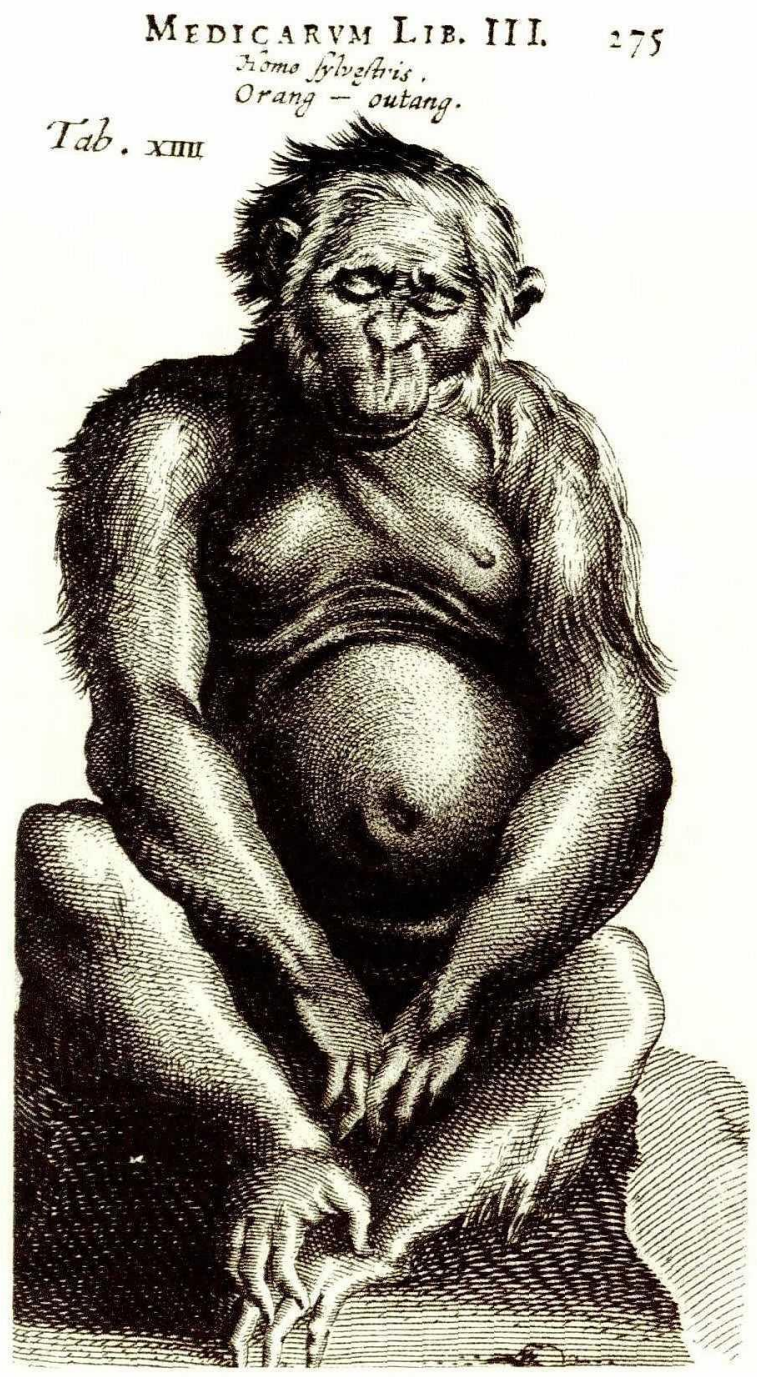

Abb. 17 Homo sylvestris. Orang-outang, aus: N. Tulp: Observationum medicarum libri tres, Amsterdam 1641, Taf. 14. 